\title{
The Plastic Adaptation to Pathology in Psychiatry Are Patients with Psychiatric Disorders Pathological Experts?
}

\author{
Ali AMAD M.D, PhD ${ }^{1,2}$; Paul EXPERT PhD ${ }^{1,3,4}$; Louis-David LORD MSc ${ }^{5}$, \\ Thomas FOVET M.D, PhD², Pierre A. GEOFFROY M.D, PhD ${ }^{6}$
}

\begin{abstract}
1. Department of Neuroimaging, Institute of Psychiatry, Psychology and Neuroscience, King's College London, London SE5 8AF, UK 2. Univ. Lille, CNRS UMR 9193-PsyCHIC-SCALab, \& CHU Lille, Department of Psychiatry, F-59000 Lille, France.

3. Department of Mathematics, Imperial College London, London SW7 2AZ, United Kingdom

4. EPSRC Centre for Mathematics of Precision Healthcare, Imperial College London, London SW7 2AZ, United Kingdom

5. Department of Psychiatry, University of Oxford, Oxford, UK

6. AP-HP, GH Saint-Louis - Lariboisière - Fernand Widal, Pôle Neurosciences, Paris, France; Université Paris Diderot, UMR-S 1144, Paris, France.
\end{abstract}

\section{Corresponding author:}

Dr Ali Amad

Centre for Neuroimaging Sciences,

Box 089, Institute of Psychiatry, Psychology \& Neuroscience

De Crespigny Park, London SE5 8AF, UK.

ali.amad@kcl.ac.uk

禺: +44 (0)203228 3060; Fax: +44(0) 2032282116

\section{5 words}

2 tables

2 figures 


\section{Abstract (170 words)}

Psychiatric disorders share the same pattern of longitudinal evolution and have courses that tend to be chronic and recurrent. These aspects of chronicity and longitudinal evolution of psychiatric disorders are currently studied under the neuroprogression framework. Interestingly, considering the plasticity of the brain, it is necessary to emphasize the bidirectional nature of neuroprogression. We review evidence highlighting alterations of the brain associated with the longitudinal evolution of psychiatric disorders from the framework of neuroplastic adaptation to pathology. This new framework highlights that substantial plasticity and remodelling may occur beyond the classic neuroprogressive framework, which is characterized only by loss of grey matter volume, decreased brain connectivity, and chronic inflammation. We also integrate the brain economy concept in the neuroplastic adaptation to pathology framework, emphasizing that to preserve its economy, i.e., function, the brain learns how to cope with the disease by adapting its architecture. This approach can disentangle both the specific pathophysiology of psychiatric symptoms and the adaptation to pathology, thus offering a new framework for both diagnosis and treatment.

Key words: neuroplasticity; neuroprogression; psychiatric disorders; brain economy; severe mental illness; biomarkers. 


\section{Introduction}

The prevalence, severity, and overall burden of morbidity and mortality represented by psychiatric disorders reflect an urgent global public health priority (Buka, 2008; Whiteford et al., 2013). However, to date, objective measures of psychopathology and biomarkers that reliably delineate normal from disease states, or one disease state from another, are still lacking (Akil et al., 2010; Krystal and State, 2014). Indeed, for the past 40 years, genomics, neurobiology, cognitive neuroscience, neuroimaging and pharmacology development have challenged the psychiatric diagnostic nosology boundaries (Bellivier et al., 2013; Krystal and State, 2014). Interestingly, the transdiagnostic approach appears as a paradigm shift in the understanding of psychiatric disorders. Indeed, nosological systems, such as the DSM-5 and ICD-10, define the different psychiatric disorders as distinct, independent, and categorical constructs (Krueger and Eaton, 2015). However, psychiatric diagnosis has always been challenging due to the complexity and heterogeneity of the symptoms that may occur in a particular disorder and the potentially confusing comorbidities with other psychiatric disorders (McHugh, 2005). For several years, the transdiagnostic approach has been developed with the objective of discerning possible commonalities that may highlight new neurobiological or therapeutic avenues, especially by focusing on certain clinical dimensions or symptoms such as psychosis (van Os and Reininghaus, 2016), anhedonia (Zhang et al., 2016), or compulsivity (Gillan et al., 2016). Beyond the transdiagnostic approach of symptoms, psychiatric disorders also share the same pattern of longitudinal evolution with courses that tend to be chronic and recurrent. This chronic nature is currently studied under the neuroprogression framework, defined as the changes associated with the pathological rewiring of the brain that takes place with the progression of severe mental disorders (Berk, 2009). Neuroprogression has been associated with loss of grey matter volume, chronic inflammation, changes in growth factors, oxidative stress and mitochondrial dysfunction across a range of disorders such as bipolar disorder (BD), major depressive disorder (MDD) or schizophrenia (SCZ) (Berk et al., 2011b; Davis et al., 2014; Moylan et al., 2013). 
While considering the plasticity of the brain (i.e., the ability of the brain to respond to intrinsic or extrinsic stimuli by reorganizing its structure, function and connections (Cramer et al., 2011)), it has recently been suggested that it is necessary to emphasize the bidirectional nature of neuroprogression (Moylan et al., 2013). Substantial plasticity and remodelling can then be associated with the evolution of psychiatric disorders, and it becomes necessary to revise the current "deficitoriented" models (Palaniyappan et al., 2017). Indeed, even if neuroplasticity (NP) was initially thought to be limited to critical periods of brain development, it is now largely accepted that NP occurs throughout the lifespan (Pascual-Leone et al., 2005). Several famous neuroimaging investigations demonstrate adaptive neuroplastic modifications in the structure (Draganski et al., 2004; Driemeyer et al., 2008; Maguire et al., 2000) and function (Amad et al., 2017; Lewis et al., 2009) of the human brain in response to environmental demands in healthy adults and in patients with psychiatric disorders (e.g., (Amad et al., 2014; Buckholtz and Meyer-Lindenberg, 2012; Eack et al., 2010; Goldapple et al., 2004; Stephan et al., 2006a)).

In this article, we review evidence that focuses on alteration of the brain associated with the longitudinal evolution of psychiatric disorders from the perspective of neuroplastic adaptation to pathology. This new concept highlights that substantial plasticity and remodelling may occur beyond the classic neuroprogressive framework. 


\section{Neuroprogression and the longitudinal evolution of psychiatric disorders}

The concept of "neuroprogression" has been proposed to account for changes observed through the natural course of psychiatric disorders (Kapczinski et al., 2014). This concept finds its origins in Europe during the mid- $19^{\text {th }}$ century, when Jean-Pierre Falret, Karl-Ludwig Kahlbaum and Joseph Guislain developed the idea of a longitudinal evolution of psychiatric disorders, even until recovery, and emphasized the importance of including longitudinal factors in psychiatric diagnosis. In 1867, Wilhelm Griesinger described these emerging conceptions of neuroprogression as " $a$ constant progressive course, which may proceed even to complete destruction of the mental life" (Griesinger, 1867). These historical observations of patients presenting with early stages of discrete symptoms that move towards progressive alterations are still relevant with staging models going from very early stages defined by at-risk or latency stages to late or end-stages (Scott et al., 2013) (Figure 1). Neuroprogression has been associated with not only chronic but also recurrent courses. Indeed, psychiatric disorders (e.g., MDD, BD, SCZ, panic disorder (PD), obsessive-compulsive disorder (OCD), anorexia nervosa) show very high relapse rates, and each episode of illness increases the likelihood of future episodes, a phenomenon also known as kindling (Langen et al., 2011; Post, 2007) (Table 1). Interestingly, similar mechanisms seem to be involved in addictive disorders with significant changes in neural circuitry mediating the motivational system as the disorder progresses, which could drive compulsive drug taking and narrowing the behavioural repertoire to drug seeking (Koob and Moal, 2005). BD is probably the disorder that has been the most studied from the perspective of neuroprogression. BD is a recurrent chronic disorder characterized by fluctuations in mood state and energy affecting more than $1 \%$ of the world's population (Grande et al., 2016). In BD, increased recurrences are associated with a risk of rapid cycling between the depressive and manic states (Berk et al., 2011a; Cramer et al., 2011; Kapczinski et al., 2014). This stepwise progression exists not only in clinical symptoms but also in treatment response, neurobiology, and functional impairment (Berk, 2009; McGorry et al., 2010, 2006). Berk developed the concept of "pathological rewiring of the brain" 
to explain the links between clinical evolution of $\mathrm{BD}$ and the underlying neuroprogression (Berk, 2009). This approach finds its roots in the neurosensitization model proposed by Post and the allostatic load hypothesis by Kapczinski et al. (Kapczinski et al., 2008; Post, 1992). The neurosensitization model postulates that sensitization to both stressors and episodes leads to alterations of neuronal activities that may be transduced at the gene expression level (e.g., the protooncogene c-fos and related transcription factors) (Post, 1992). These biochemical and anatomical parameters evolve over time as a function of recurrences and lead to poorer pharmacological responses in affective disorders (Post, 1992). The allostatic load hypothesis suggests a direct modulation of brain circuits by stress and episodes leading the patients to become more vulnerable to subsequent environmental stressors, drug abuses, and symptomatic episodes (Kapczinski et al., 2008). Numerous biochemical mediators underlying this neuroprogression and stress sensitization have been found to be involved, such as inflammatory processes (including the CRP, IL-6, IL-10, and TNF- $\alpha$ ), neurotrophins (including the peripheral blood BDNF), and oxidative stress processes (including the glutathione system (Berk, 2009; Maes et al., 2016; Munkholm et al., 2016)).

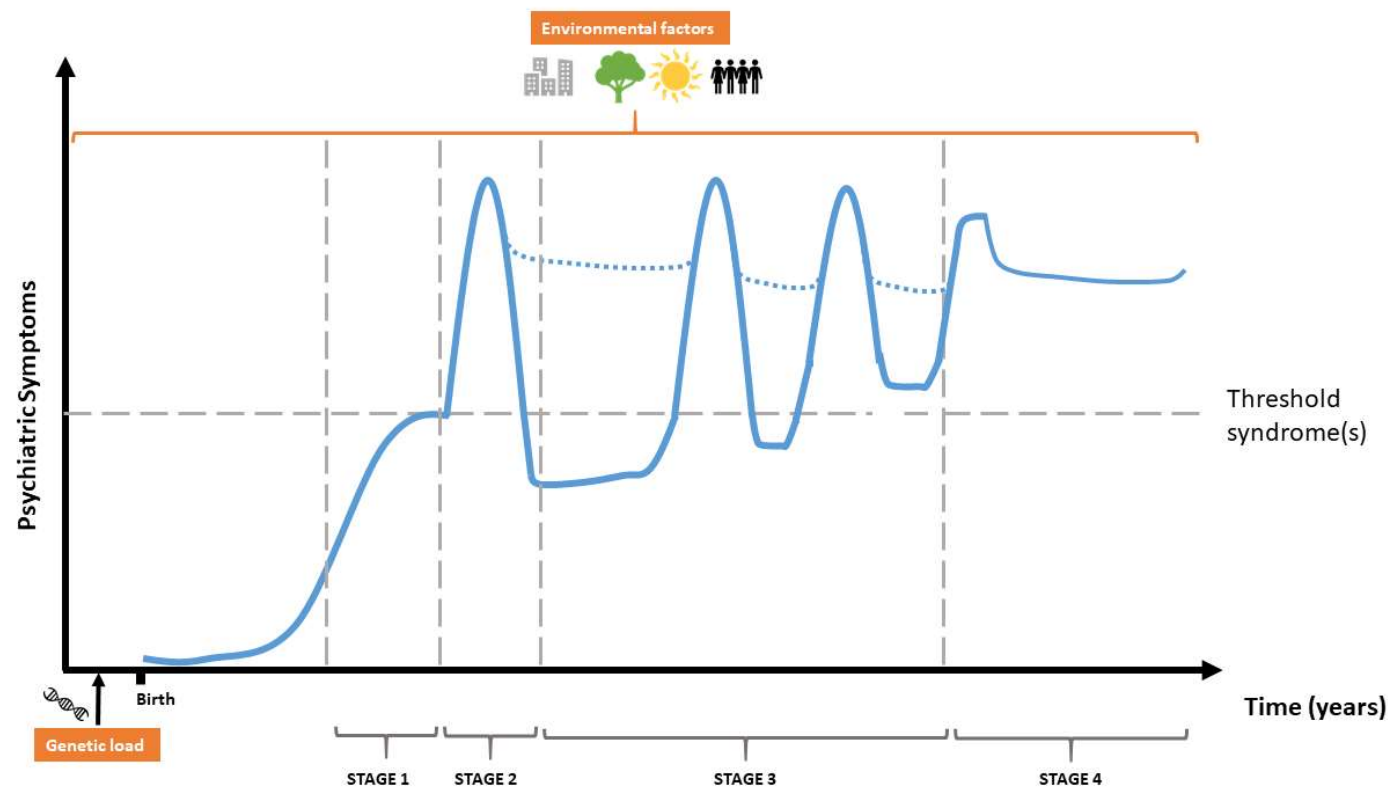

Figure 1. The clinical staging model proposed that major psychiatric disorders develop from an "atrisk" asymptomatic state, through an initial stage of undifferentiated general symptoms (e.g., mild 
anxiety, sleep disturbance, depressive symptoms) (stage 1), followed by a worsening of these existing symptoms and the acquisition of new symptoms, associated with greater syndromal specificity and with behavioural and functional decline. Further progression of illness may then take place, resulting in the occurrence of a first episode of a full-threshold syndrome(s) (stage 2), which may be followed by the development of recurrent or persistent symptoms (dotted lines) (stage 3) or even severe, treatment-resistant illness (stage 4). Interactions, between endogenous (e.g., genes) and exogenous (e.g., drug, urbanicity, social relationships, rhythms) factors, influence the risk of developing a psychiatric disorder as well as the recurrence and persistence of symptomatic episodes.

Neuroprogressive features have also been observed in other psychiatric disorders. MDD is associated with poorer symptomatic, treatment and functional outcomes in patients with earlier disease onset and an increased number and length of depressive episodes (Table 1) (Moylan et al., 2013). Stage-related structural brain changes such as a reduced hippocampal volume are influenced by illness duration, age of onset and episode frequency in patients with MDD (Eker and Gonul, 2010; Videbech and Ravnkilde, 2004). Moreover, it has been shown that multiple biochemical pathways (inflammation, stress axis, oxidative stress, disturbance to mitochondrial energy production and cell survival mechanisms and gene transcription alterations) interact simultaneously to cause cellular damage that underwrites the neuroprogression in MDD (Moylan et al., 2013).

Table 1: Clinical characteristics of psychiatric disorders or symptoms from the perspective of the repetitiveness and rates of recurrence or relapse.

\begin{tabular}{|c|c|}
\hline Disorder & Rate of relapse and clinical aspect of repetitiveness \\
\hline $\begin{array}{c}\text { Depressive } \\
\text { disorder }\end{array}$ & $\begin{array}{l}\text { - Highly recurrent disorder (Moylan et al., 2013). } \\
\text { - The risk of recurrence after a first major depressive episode is 50\% and } \\
\text { increases with subsequent episodes (Kendler et al., 2000; Post, 1992). } \\
\text { - Individuals with a history of depression will have five to nine separate } \\
\text { episodes in their lifetime (Burcusa and lacono, 2007). }\end{array}$ \\
\hline Schizophrenia & $\begin{array}{l}\text { - Long-term course of illness is typically characterized by multiple relapses, } \\
\text { persistence of symptoms and enduring cognitive and functional deficits } \\
\text { (Andreasen et al., 2005). } \\
\text { - } 60-90 \% \text { of relapses occur within two years of a first psychosis episode after }\end{array}$ \\
\hline
\end{tabular}




\begin{tabular}{|c|c|}
\hline & $\begin{array}{l}\text { treatment reduction/discontinuation (Emsley et al., 2013). } \\
\text { - } 30 \% \text { have auditory hallucinations that are resistant to treatment (Shergill et } \\
\text { al., 1998). }\end{array}$ \\
\hline Bipolar disorder & $\begin{array}{l}\text { - Highly recurrent disorder: } 60 \% \text { relapse two years after a major episode (Gitlin } \\
\text { et al., 1995). } \\
\text { - In patients receiving treatment according to contemporary practice } \\
\text { guidelines, } 58 \% \text { achieve recovery and } 49 \% \text { develop recurrences over a } 2 \text {-year } \\
\text { period (Perlis et al., 2006). } \\
\text { - Patients change symptom status (asymptomatic, subthreshold levels, full- } \\
\text { blown major depression and mania) an average of } 6 \text { times per year and } \\
\text { polarity (full-blown major depression or mania) more than } 3 \text { times per year } \\
\text { (Judd et al., 2002). }\end{array}$ \\
\hline Panic disorder & $\begin{array}{l}\text { - Recurrent panic attacks (Roy-Byrne et al., 2006). } \\
\text { - Recurrence rate of } 25 \% \text { two years after remission (Scholten et al., 2013). }\end{array}$ \\
\hline $\begin{array}{l}\text { Obsessive- } \\
\text { compulsive } \\
\text { disorder }\end{array}$ & $\begin{array}{l}\text { - Recurrent and persistent thoughts and repetitive behaviours (Abramowitz et } \\
\text { al., 2009). } \\
\text { - } 60 \% \text { relapse five years after remission (Eisen et al., 2013). }\end{array}$ \\
\hline
\end{tabular}

Recently, it has been suggested that SCZ is also characterized by neuroprogressive features at a clinical and neurobiological level (Davis et al., 2014). Indeed, SCZ has been associated with progressive enlargement of brain ventricles (Van Haren et al., 2012) mediated by abnormalities in the cortical grey matter and reductions in white matter surface area (Colibazzi et al., 2013; Vita et al., 2012). These changes may correlate with symptoms and disorder progression (Chan et al., 2011; Vita et al., 2012). Like BD and MDD, SCZ has been associated with chronic inflammation, oxidative stress and mitochondrial dysfunction (Buonaguro et al., 2017; Davis et al., 2014).

In summary, there is a growing scientific literature observing that multi-scale changes (from behaviour to molecular levels) appear during the evolution of psychiatric disorders, from very early 
"at-risk" phases to different major clinical stages (McGorry et al., 2014; Scott et al., 2013). These changes may be the consequence of neuroprogression processes that lead to more permanent alterations in late stages. However, it is necessary to consider and emphasize the bidirectional nature of this neuroprogression: substantial plasticity and remodelling can occur (Moylan et al., 2013), especially in light of the concept of the economy of the brain. 


\section{The economy of the brain}

The brain is more than an intricate network of neurons connected in an immutable fashion; it is capable of adaptation to its internal and external environment, which endows it with great resilience as a system. Its structure and function continuously change throughout the lifespan of an individual, sometimes drastically due to injury or illness (Bullmore and Sporns, 2012). Neuroplasticity, as described earlier, is arguably one of the key mechanisms that has enabled humans to survive and adapt as a species. In this section, we argue that it is this same capacity for learning and adaptation that may be responsible for the brain's demise in chronic psychiatric disorders.

In this paper, we contrast brain evolution and brain adaptation. Brain evolution is the process that has led to general structural and functional organization of the normal brain via genetic mutations and natural selection (Somel et al., 2013). Brain adaptation, on the other hand, refers to the changes the brain undergoes post fertilization, either via normal ageing or in response to changes in its environment and integrity such as learning, trauma or, as we argue here, psychiatric disorders (Amad et al., 2016; de Kloet et al., 2005).

With the principle of least action guiding the evolutionary process, we can safely assume that the healthy brain is currently the most energy-economic version of the system that yields healthy brain function (Hutto, 1999). As a result, it is argued that the brain dynamics are close to an optimal state, i.e., a "sweet spot" (Expert et al., 2011), allowing the maximal response range (Kinouchi and Copelli, 2006) while reducing energy expenditures incurred by the structural and functional architecture of the brain (Bullmore and Sporns, 2012; Chialvo, 2010).

The preservation of homeostasis is paramount to keeping brain dynamics in this operating "sweet spot" and occurs at the global level, where evidence shows that the brain is operating close to an attractive critical point (Expert et al., 2011) that allows for a trade-off between segregation and integration. This phenomenon has been proposed as a basis for a model that reconciles multi-level 
brain function findings in health and in psychiatric disorders such as SCZ (Turkheimer et al., 2015). The neurobiological underpinnings of critical brain dynamics are not fully understood, but the available evidence suggests that a complex synergy between the organization of the brain's structural connectome and the excitation-to-inhibition balance in local neuronal populations is likely at play (Froemke, 2015; Lord et al., 2017; Shew et al., 2011). One of the consequences of a system being close to criticality is the similarity of processes at different levels of description. In the case of homeostasis, this similarity is reflected by the synaptic adaptation hypothesis (Tononi and Cirelli, 2014), which states that sleep is paramount to regulating synaptic adaption to learning. Synaptic plasticity forms the basis for brain adaptability and our capacity to learn, and these structural changes are also reflected by functional brain changes, which provides a self-similar causality chain from micro- to macroscopic scales (Amad et al., 2016).

We propose that certain psychiatric disorders are effectively the result of a brain adaptation mechanism akin to learning. The basis of our argument lies in the brain economy framework, which implies that the brain tries to remain as close as possible to its optimal state (Bullmore and Sporns, 2012; Expert et al., 2011). We regard the endogenous and/or environmental perturbations linked to the onset of chronic psychiatric disorders as long-term disturbances to normal brain function that are constantly pushing the brain economy away from its optimal healthy state (Roth et al., 2009; Rutten and Mill, 2009). This phenomenon leads the brain to develop compensatory mechanisms to adapt and preserve its function as much as possible and has been associated with the prodromal state of a psychiatric disorder (Lord et al., 2012, 2011) where, notably, functional connectivity (FC) networks may alter their topology in response to illness to preserve cognitive and behavioural output. However, these resulting new functional pathways may not be optimally supported by the structural connectome and may be energetically costly to maintain over time. We therefore hypothesize that these compensatory mechanisms are not sustainable in the long term and that the brain economy becomes overstretched. To maintain homeostasis, the brain then has to adapt to the disease and restore brain economy to a less expensive state, given the 
constraints of the disease and its progression via synaptic plasticity mechanisms akin to learning. This full adaptation means that new structural pathways are created to learn to "cope" with the illness while preserving as much as possible of the brain function and associated cognitive and behavioural outputs. At the same time, it also means that normally used pathways are abandoned over time, which is consistent with numerous imaging studies that find over-activation and under-activation patterns in the brain networks or "connectome" (Crossley et al., 2016, 2014), as well as concurrent increases and decreases in FC (Crossley et al., 2016, 2014; Lord et al., 2012, 2011). Once the brain economy is restored with respect to the new functional and structural organization, the brain finds itself in a new "optimal" yet diseased state, and the process is complete. In other words, to preserve its economy, i.e., functional dynamics and behaviour, the brain learns how to cope with the disease by adapting its structure.

Let us now formalise our proposal illustrated in Figure 2. The simplest model of the brain interacting with its environment consists of a semi-black box that takes inputs and produces outputs. Let us now restrict ourselves to a given set of inputs $\{I\}$. The brain then produces a set of corresponding outputs $\{O\}$, using its anatomical wiring and the function it supports, for a given energetic price $E$. We denote the set of output expected from a healthy individual and the associated energy as $\{O\}_{h}$ and $E_{h}$, respectively. One way to assess the mental state of a subject is to test his/her answers and/or behavioural responses to a pre-established set of items on the basis of which he/she will be deemed ill, at-risk or in the healthy range. In our language, this means that if the outputs from a subject deviate more than a given quantity, that individual will be classified as prodromal, diseased, etc., and we denote such outputs as $\{O\}_{d}$ and an associated energy expenditure $E_{d}$. As reviewed in the next section, functional and structural dysconnectivity have been shown to be present in many psychiatric diseases, and we hypothesize that structural connectivity (SC) and FC indeed deviate from the healthy control baseline in patients. 

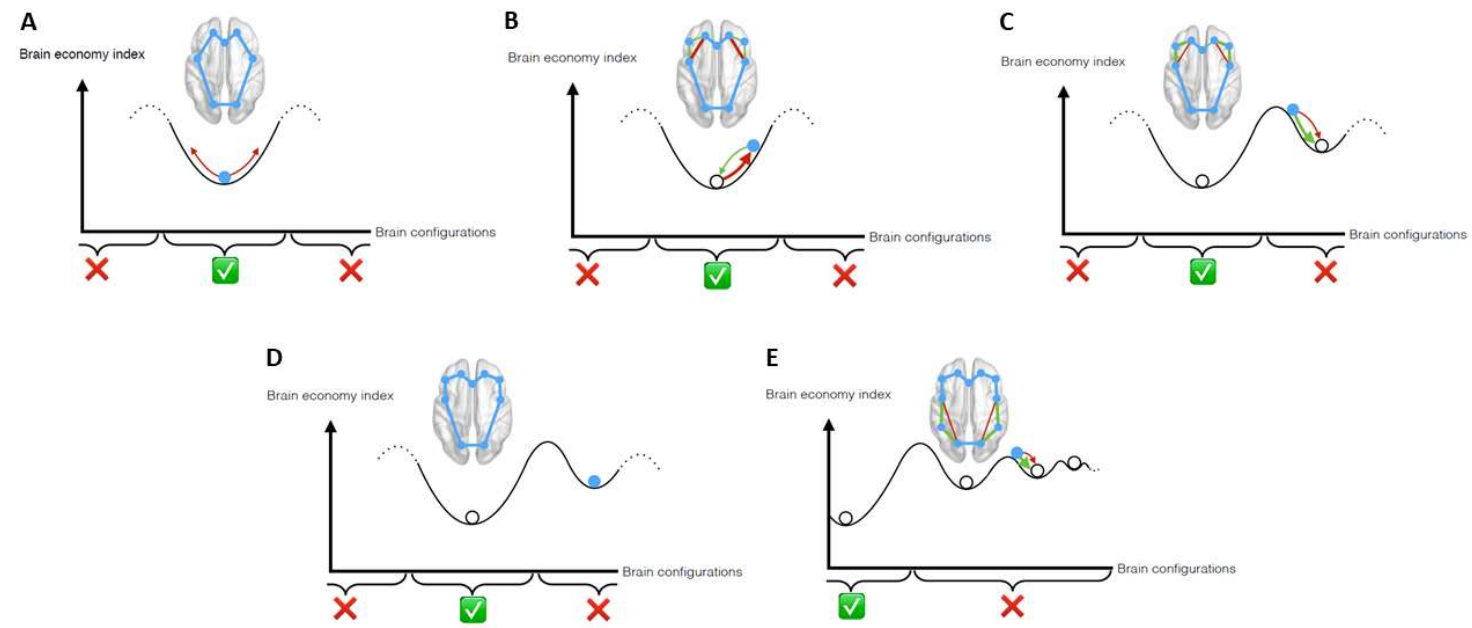

\section{Figure 2}

The brain economy paradigm posits that the brain minimizes energy expenditure for a specific functional and structural configuration (FSC). The brain economy index (BEI) then represents a measure of optimality of brain function with respect to energy expenditure and cognitive outputs that is minimized for a healthy FSC.

Legend:

- Blue circles: current FSC

- Empty circles: locally optimal FSC

- Red arrows and links: endogenous and exogenous factors affecting the FSC

- Green arrows and links: compensatory mechanisms that try to maintain the FSC into its local optimal

- The $x$-axis corresponds to possible FSC, and the $y$-axis corresponds to the associated BEl that takes into account energy expenditure and cognitive outputs of the corresponding FSC

(A) The brain is currently in its optimal healthy FSC condition, and any perturbation would put strain on it.

(B) Endogenous and exogenous factors put stress on the FSC and push it away from its optimal point, while compensatory mechanisms try to counter these effects. The compensatory mechanisms cause increased energy expenditure, while perturbating factors cause decreases in cognitive outputs.

(C) When the perturbative factors are stronger than the compensatory mechanisms, as in (B), the compensatory mechanisms overstrain the brain FSC and eventually lead to a breakdown (e.g., first psychotic episode) and a reconfiguration and relaxation of the system, dominated by the compensatory mechanisms, into a new FSC that will be locally optimal, i.e., lower energy expenditure than during intense straining and suboptimal, but comparatively improved, cognitive outputs.

(D) The FSC has settled and adapted to its new local optimum. Being less optimal than the healthy FSC, the new FSC is less stable.

(E) Lower barriers, particularly in the direction of worsened symptoms/state, make it more difficult for compensatory mechanisms to contain further endogenous and exogenous perturbations. This phenomenon leads to faster recurrence associated with increasingly worse subject cognitive outputs. 
Our argument posits that compensatory mechanisms will try to preserve the outputs as close as possible to the healthy range in response to exogenous and/or endogenous constraints, doing so by adapting first brain function (FC) and then its structure (SC), at the cost of an increased energy expenditure.

We thus have two quantities that depend on $S C$ and $F C$, the outputs $\{O\}\left(S C_{i}, F C_{i}\right)$ and the energy expenditure $E\left(S C_{i}, F C_{i}\right)$. These values define the brain economy index $(\mathrm{BEI})$, which measures the deviation of the brain economy of a state $i$ from a healthy state by combining the quality of the brain outputs and its energy expenditure as follows:

$$
B E I\left(\{O\}_{i}, E\right)=\alpha\left|\{O\}_{h}-\{O\}_{i}\right|+\beta\left|E_{h}-E_{i}\right|
$$

The constant $\alpha$ and $\beta$ weight the two contributions and ensure that the BEI is dimensionless.

We now present Figure 2 to show how the BEI can be used to characterize the evolution and chronicity of psychiatric diseases. In this figure, each minimum corresponds to a combination of FC, SC and $\{O\}_{i}$, with the deeper one corresponding to the healthy baseline. Disease-associated exogenous and/or endogenous perturbations will first lead to a modification of FC patterns to maintain $\{O\}_{h}$, at the cost of an increased energy expenditure, raising the BEI (panel $\mathrm{B}$ ). When the brain metabolism becomes overstretched, a symptomatic episode occurs, and the system moves into a new basin of $\{O\}_{d}$. The corresponding outputs are no longer on par with the healthy baseline but allow the energy expenditure to decrease, while reinforcing the changes in FC (panel C) and eventually leading to change in the SC via synaptic plasticity mechanisms, when the system reaches a new minimum of the BEI, as expected from the economy of the brain theory. This new minimum is higher than the healthy baseline because of SC and FC changes and the associated pathological outputs $\{O\}_{d}$ (panel D). This new minimum is more unstable than the original healthy minimum because its $\mathrm{BEI}$ is closer to the level at which disease-related episodes occur. Therefore, the process is more prone to repeating itself, leading to more frequent episodes and disease progression over time (panel E). 


\section{Highlighting the plastic adaptation to pathology with neuroimaging}

\subsection{Structural MRI}

Neuroimaging evidence shows both differences in structural features associated with their relevant functions and changes in structural features (grey matter volume and cortical thickness) when long-term neural activity patterns are changed by experience. These changes probably involve many coordinated brain regions that can be explored with the study of changes in the white matter pathway microstructure and the study of white matter connectivity with diffusion tensor imaging (DTI). Common measures of DTI include fractional anisotropy (FA), reflecting anatomical white matter features such as axon calibre and myelination. The interpretation of variations in FA is not straightforward; however, a reduced FA is commonly interpreted as a loss in white matter integrity (Allen et al., 2012; Johansen-Berg and Rushworth, 2009), whereas an increased FA is thought to reflect an increase in white matter connectivity (Dong et al., 2004). Many structural neuroimaging studies have thus shown not only a loss of matter in brain volumes among patients suffering from neuropsychiatric disorders (Goodkind et al., 2015); brain volume increases have also been demonstrated in psychiatric disorders such as SCZ, BD, autism or OCD.

In SCZ, grey and white matter reductions are well documented (Haijma et al., 2013). However, the recent study of van Erp et al. (van Erp et al., 2016) involving more than 2000 patients with SCZ showed that compared with controls, individuals with SCZ exhibited significantly larger pallidum volumes. Interestingly, duration of illness and age were positively associated with pallidum and putamen group contrast effect size. Nonetheless, as highlighted by the authors, these changes may reflect the cumulative effects of antipsychotic medication treatment on basal ganglia volumes reported especially for the putamen (Gur et al., 1998; Li et al., 2012), even if a disease-related age effect cannot be excluded because larger pallidum volumes in unmedicated, non-ill relatives of individual with SZ have also been reported (Oertel-Knöchel et al., 2012; Yang et al., 2012). 
In BD, a meta-analysis of grey matter abnormalities using voxel-based morphometry studies revealed that in chronic patients, longer duration of illness was associated with increased grey matter in a cluster that included the basal ganglia, subgenual anterior cingulate cortex and amygdala (Bora et al., 2010).

In OCD, increased grey matter volume has been demonstrated in the basal ganglia (putamen and caudate) (Radua et al., 2010; Radua and Mataix-Cols, 2009; Rotge et al., 2010; Zarei et al., 2011), the thalamus (Kim et al., 2001) and cortical regions such as left orbital frontal gyrus, right middle frontal gyrus, left middle temporal gyrus, precentralgyrus, and postcentralgyrus (Tang et al., 2016). Bilateral cerebellar volume increases and age-related increases in putamen, insula and orbito-frontal cortex volumes have also been reported in a recent mega-analysis (de Wit et al., 2014).

In autism, increased grey matter volumes are well known and replicated findings in regions including areas of the temporal and parietal lobes (Hardan et al., 2006; Waiter et al., 2004; Yang et al., 2016).

Finally, in social anxiety disorder, Talati et al. demonstrated that compared with healthy controls, patients exhibited greater grey matter in the left parahippocampal and middle occipital, bilateral supramarginal and angular cortices, and left cerebellum (Talati et al., 2013). For other anxiety disorders, Shang et al. showed increased grey matter volumes in the right dorsolateral prefrontal cortex in drug-naïve patients with comorbid depression-anxiety (Shang et al., 2014).

\subsection{Functional MRI and functional connectivity}

Neuropsychiatric disorders are often coined as dysconnectivity syndromes (Buckholtz and Meyer-Lindenberg, 2012). The dysconnectivity hypothesis suggests that the existence of impaired connectivity between different brain regions is responsible for abnormal functional integration within neural networks. This impaired connectivity might be associated with an impaired control of synaptic plasticity (Friston, 1998; Stephan et al., 2009, 2006b). The underlying mechanisms for dysconnectivity remain unknown but likely involve both genetic (Brennand et al., 2011) and 
environmental factors (Sullivan et al., 2003), leading to early alterations in the development of brain wiring and impaired experience-dependent synaptic plasticity (Stephan et al., 2006b). Recently, resting-state FC analyses have been widely used to investigate neuroplastic modifications. FC corresponds to the temporally correlated, low-frequency spontaneous fluctuations of blood oxygen level-dependent (BOLD) signals across brain regions that occur when a participant is not performing an explicit task (Fox and Raichle, 2007). These temporal correlation patterns are not random, and specific networks, such as the default mode network (Greicius et al., 2003), have been reliably identified across studies and participants. Moreover, it is now widely accepted that the strength of correlations within and between networks has behavioural relevance (Amad et al., 2014a; GuerraCarrillo et al., 2014). Interestingly, it has been proposed that FC is an effective measure of plasticity and that activity patterns reflect the history of repeated synchronized activation between brain regions (Buckner and Vincent, 2007; Guerra-Carrillo et al., 2014).

Consistent with the bidirectional nature of the plastic adaptation to pathology outlined above, neuroimaging investigations of FC in psychiatric disorders often reveal not only a loss of FC but also concurrent FC increases in specific neural circuits (Crossley et al., 2016, 2014; Lord et al., 2012, 2011). Importantly, the reported FC increases have been shown in many studies to correlate with the clinical expression of the disease, which suggests that increased FC, as decreased FC, is a pathologically informative feature of brain networks in neuropsychiatric disorders.

In SCZ, a number of studies have found connectivity increases across several brain systems, including the default mode network, cortico-striatal, and thalamocortical pathways (Anticevic et al., 2014; Fornito et al., 2013; Fornito and Bullmore, 2015; Hoffman et al., 2011; Whitfield-Gabrieli et al., 2009). Furthermore, in many cases, these FC increases have been positively correlated with symptom severity (Anticevic et al., 2014; Fornito et al., 2013; Hoffman et al., 2011; Whitfield-Gabrieli et al., 2009). A recent meta-analysis of 52 seed-based voxel-wise resting-state FC studies showed that SCZ was characterized not only by hypo-connectivity within multiple networks but also by hyperconnectivity between the affective network and the ventral attention network (Dong et al., 2018). 
Interestingly, a brain-wide FC study in 789 participants (343 patients) recently showed stage-specific functional dysconnectivity across first-episode and chronic stages of SCZ. In first-episode patients, $90 \%$ of the functional connectivity changes (from healthy controls) involved the frontal lobes (including Broca's area), whereas for chronic patients, functional connectivity differences extended to wider areas of the brain, including not only reduced thalamo-frontal connectivity but also increased thalamo-temporal and thalamo-sensorimotor connectivity (Li et al., 2017).

FC increases have also been reported in mood disorders including BD and MDD. Patients with BD notably show greater connectivity between the amygdala and frontal cortical structures including the anterior cingulate cortex and medial prefrontal cortex compared to healthy subjects (Brady et al., 2016; Cerullo et al., 2012; Favre et al., 2014), which, in turn, has been correlated with the duration of the disease. In MDD, patients show increased FC in the default mode network (Goya-Maldonado et al., 2016; Greicius et al., 2007), which notably correlates with the number of depressive episodes. Increased fronto-striatal connectivity between the caudate and dorsal prefrontal cortex has also been found in MDD and is positively correlated with the severity of the disorder (Furman et al., 2011). Hyper-connectivity between the anterior temporal and subgenual cortices is also a risk marker of subsequent recurring depressive episodes in MDD patients (Lythe et al., 2015).

Finally, increased FC has also been found in other disorders such as autism spectrum disorder (ASD) or in anorexia nervosa (AN). Individuals with ASD showed increased FC between primary sensory networks and subcortical networks (thalamus and basal ganglia), and the strength of such connections was associated with the severity of autistic traits in the ASD group (Cerliani et al., 2015). Additionally, in AN, increased FC has been observed at rest in the fronto-parietal network, supporting the hypothesis of excessive cognitive control in AN, and of the anterior insula with the default mode network, which may reflect the high levels of self- and body-focused ruminations (Boehm et al., 2014).

Neuroimaging evidence in psychiatric disorders such as SCZ, BD, autism or OCD highlights the plastic adaptation to pathology, with many structural and functional neuroimaging studies observing 
that there is not only a loss of matter in different brain region volumes or decreased FC but also brain volume increases, along with structural and FC increases or decreases across brain regions. Interestingly, these changes of volume and connectivity are associated with anatomo-clinical correlates, including the disorder progression, the number of episodes of illness, and the duration of disease, highlighting the role of dysconnectivity processes in the adaptation to pathology. 


\section{The neuroplastic adaptation to pathology framework}

After having highlighted the high rates of recurrence or relapse in psychiatric disorders from the neuroprogression perspective, the constraints on the brain economy function, and the increases in brain volume and structural and/or FC that may be associated with the clinical features and duration of most major psychiatric disorders, we thus propose to integrate this evidence in the framework of neuroplastic adaptation to pathology. Adaptation to pathology can be defined as "the plastic modification of the brain associated with the longitudinal evolution of psychiatric disorders whose courses tend to be recurrent and progressive; with a very high rate of relapse, each episode of illness increases the likelihood of future episodes" (Table 1). Indeed, the brain is essentially a plastic organ, and it is now well known that the repetition of nearly all motor and cognitive skills and processes leads to structural and functional neuroplastic modifications, strengthening those pathways (Amad et al., 2017; Draganski et al., 2004; Green and Bavelier, 2008; Linden, 2006; PascualLeone et al., 2005; Sagi et al., 2012). Considering the intensity, duration and repetition of psychiatric episodes (Bremner, 2006; Pol et al., 2008), we believe that the brain will also adapt to these episodes. Moreover, the repetition of cognitive or motor skills is known to be executed faster the more they are practised as a result of neuroplastic changes, until behaviours are executed habitually or automatically in a manner that consumes fewer neural resources, a natural consequence of the brain economy framework (Ashby et al., 2010). Based on these observations, we propose a neuroplastic theoretical framework that posits that patients with psychiatric disorders are unfortunate "pathological experts". The repetition of psychiatric episodes and/or symptoms then leads to experience-dependent neuroplastic modifications that increase the likelihood of future episodes and/or symptoms, which ultimately leads to a neuroplastic vicious circle associated with increases in repetitiveness and decreases in behavioural flexibility (Amad et al., 2014b; Graybiel, 2008), regardless of extrinsic environmental triggers. 
From the perspective of the plastic adaptation to pathology, the review of neuroimaging studies presented in this paper highlights the importance of the basal ganglia and cortical-subcortical connectivity, which appear to be associated with the longitudinal course of psychiatric disorders. The basal ganglia are a set of deep forebrain nuclei consisting of the striatum (caudate and putamen), globus pallidus (internal and external segments), subthalamic nucleus, and substantia nigra (pars reticulata and pars compacta). Interestingly, repetitive behaviours or repetitive cognitive activities are supposed to emerge as a result of experience-dependent plasticity in different basal ganglia-based circuits (Ashby et al., 2010; Yin and Knowlton, 2006) connected to other brain regions, including the cerebral cortex, thalamus, several brainstem nuclei, and the cerebellum, to form a network with both open- and closed-loop circuitry (Caligiore et al., 2017). Thus, although further investigation is required, we believe cortical-subcortical and cerebellum networks related to learning and habits could play a major role in the repetition of episodes of illness involved in psychiatric disorders (Graybiel, 2008).

The neuroplastic framework presented here fits well with the dysconnectivity model of psychiatric disorders, which postulates that psychiatric symptoms are associated with impairments in structural and functional brain connectivity in the networks that underpin the functions of everyday human experience (i.e., the cognitive, affective, motor, motivational, and social networks) (Buckholtz and Meyer-Lindenberg, 2012). Abnormal connectivity (decreased or increased) between brain areas is associated with impaired control of synaptic plasticity and its underlying mechanisms, which involves both genetic and environmental factors and leads to alterations in brain wiring and impaired experience-dependent synaptic plasticity (Amad et al., 2014; Stephan et al., 2006a). Thus, rather than the flexible networks with interactions within and between populations of neurons that allow for efficient communication in healthy subjects, patients with psychiatric disorders are characterized by rigid dysconnectivity of the neural networks (Buckholtz and Meyer-Lindenberg, 2012). In our framework, the strength of this dysconnectivity is reinforced by the repetition and duration of psychiatric symptoms or episodes (Figure 2). 


\section{Discussion}

The framework of adaptation to pathology is a paradigm shift that leads to a novel conceptualization of the pathophysiology of psychiatric disorders and emphasizes the influence of neuroplastic adaptations to symptom repetition that are inherent to the brain's ability to adapt (Pascual-Leone et al. 2005). We believe that this framework could make it possible to disentangle the specific pathophysiology of psychiatric symptoms, on the one hand (Buckholtz and MeyerLindenberg, 2012), and the pathophysiology of the adaptation to pathology, on the other hand (Figure 2). Fascinatingly, two large-scale systematic meta-analyses of structural MRI and task-fMRI studies across multiple psychiatric diagnoses failed to identify diagnosis-specific effects (Goodkind et al., 2015; Sprooten et al., 2016). It was then suggested that the abnormalities in brain regions and networks observed in individual MRI studies may reflect brain disorder-general conditions that facilitate the emergence and persistence of symptoms but are insufficient to explain symptomatic variability across disorders (Sprooten et al., 2016). The plastic adaptation to pathology also provides a natural framework encompassing the neuroprogression hypothesis. As it has been specifically suggested for schizophrenia, we support the view that progressive changes in psychiatric disorders may not represent a deficit or decompensation process per se but that they could be the result of a distributed, nevertheless inefficient, multi-scale reorganization response (Palaniyappan, 2017). Moreover, the concept developed here is a natural consequence of the economy of the brain and fits with the dysconnectivity model of psychiatric disorders. Consideration of the adaptation to pathology framework should aid the integration of the vast and complex translational data across the genomic, neuronal, and behavioural levels. Indeed, it is essential to leverage novel methods for finding patterns and structure in complex, multi-scale datasets from big data and complexity science to develop methodological frameworks to test clinically relevant hypotheses.

The same idea, developed here from a neuroimaging perspective, can then be developed with the genetic approach of psychiatric disorders. Indeed, even if the heritability of psychiatric 
disorders is important, most genes are shared between disorders, and few genes have been strongly associated with these disorders (Brainstorm Consortium et al., 2018). We believe that in one disorder, several genetic pathways interact, involving pathways associated with the development of symptoms and pathways associated with the plastic adaptation to pathology. Thus, vulnerability in the genetic pathway involved in plastic adaptation to pathology may represent risk factors for the repetition of episodes more than the risk for the development of symptoms. Those genes could correspond to plasticity genes modulating the susceptibility to external and internal environment instead of vulnerability genes that would increase the risk of developing symptoms (Amad et al., 2014b).

Finally, the plastic adaptation to pathology framework should be considered in future fundamental and clinical studies to overcome the scientific and public health challenges posed by psychiatric disorders. To test this framework, scientific methods should not only focus on the differences between patients and disorders but also develop approaches to highlight the factors that are shared within and/or between psychiatric disorders (i.e., a transdiagnostic approach) (Table 2). For example, large brain imaging data sets from patients with different disorders (e.g., schizophrenia, MDD, BD) could be analysed using methods such as machine learning or pattern recognition to look for connectivity patterns shared by different disorders and associated with the number of episodes or duration of disease. In these studies, multimodal neuroimaging should be used to quantify the degree of reorganization to grade the severity of the underlying pathophysiological process (Palaniyappan, 2017). Additionally, as clinical and functional outcomes are not always stable at an individual level, patients should be assessed at the symptom level across time to provide appropriate variables to study in the plastic adaptation to pathology framework (Palaniyappan, 2017). 
Table 2. Recommendations for future research on the plastic adaptation to pathology

- Systematically include the duration of illness and the number or relapses in neuroimaging studies

- Focus on chronic and treatment resistant psychiatric disorders

- Development of transdiagnostic longitudinal collaborative studies including genetics and imaging data

- Development of transdiagnostic approaches to highlight the factors that are shared within and between psychiatric disorders

- Development of statistical models for longitudinal data

- Development of statistical methods to highlight what is shared by different groups instead of focusing on differences

The identification of adaptation to pathology processes in psychiatric patients will be clinically useful, particularly for understanding the high frequency of treatment-resistant psychiatric disorders and explaining why these disorders should be treated as rapidly as possible to prevent selfreinforcement of the pathological network (Sarpal et al., 2017; Scott et al., 2013). Indeed, this framework suggests that therapeutic interventions should occur as early as possible. At all stages, interventions should aim to prevent relapse and episodes by using course alteration interventions to target the neuroprogression causing a disorder to stop and, ideally, reverse its progression (Millan et al., 2016). For each stage, specific interventions should be developed to treat both processes underpinning current symptoms (symptomatic treatment) and the plastic adaptation to pathology (treatment targeting pathological networks). Whereas many symptomatic pharmacological and nonpharmacological treatments are effective in psychiatric disorders, these interventions should be guided by diagnosis for each stage with previously highlighted limits of the traditional psychiatric diagnostic system (McGorry et al., 2014). Thus, biomarkers research is expected to be able to disentangle the stages of this common progression of adaptation to pathology in psychiatric disorders. Highlighting the common patterns of psychiatric disorders that are associated with adaptation to pathology would allow us to better target and design treatments by considering them as aetiological or symptomatic. Indeed, psychotropic treatments are effective for numerous conditions, e.g., the antidepressants used to treat depressive disorder are also efficacious for, e.g., 
PD, OCD, and post-traumatic stress disorder, likely because they stop a vicious circle of dysconnectivity reinforcement (i.e., symptomatic treatment) rather than targeting the initial pathophysiology of the disorder (i.e., aetiologic treatment). Non-pharmacologic treatments such as cognitive behavioural therapy or physical exercise are also known to enhance brain plasticity and should be considered as add-ons to counteract the plastic adaptation to pathology (Rief et al., 2016). Interestingly, the neuroscience of brain plasticity provides new insights into how to drive "corrective" changes in impaired brains via intensive training that could help hinder and even reverse the adaptation to pathology (Merzenich et al., 2014). Finally, circuit-specific interventions targeting pathological networks could be promising strategies (Downar et al., 2016), using methods such as repetitive transcranial magnetic stimulation (rTMS) (Luber et al., 2017), transcranial direct-current stimulation (tDCS) (Dondé et al., 2017), or neurofeedback (Fovet et al., 2016), especially when taking the stage associated with the degree of brain reorganization following adaptation to pathology into account.

\section{Conflict of interest}

The authors declare no conflict of interest.

\section{Acknowledgements}

This research did not receive any specific grant from funding agencies in the public, commercial, or not-for-profit sectors. 


\section{References}

Akil, H., Brenner, S., Kandel, E., Kendler, K.S., King, M.C., Scolnick, E., Watson, J.D., Zoghbi, H.Y., 2010. The Future of Psychiatric Research: Genomes and Neural Circuits. Science 327, 1580-1581. https://doi.org/10.1126/science.1188654

Allen, P., Modinos, G., Hubl, D., Shields, G., Cachia, A., Jardri, R., Thomas, P., Woodward, T., Shotbolt, P., Plaze, M., Hoffman, R., 2012. Neuroimaging Auditory Hallucinations in Schizophrenia: From Neuroanatomy to Neurochemistry and Beyond. Schizophr. Bull. https://doi.org/10.1093/schbul/sbs066

Amad, A, Cachia, A., Gorwood, P., Pins, D., Delmaire, C., Rolland, B., Mondino, M., Thomas, P., Jardri, R., 2014a. The multimodal connectivity of the hippocampal complex in auditory and visual hallucinations. Mol. Psychiatry 19, 184-191. https://doi.org/10.1038/mp.2012.181

Amad, Ali, Ramoz, N., Thomas, P., Jardri, R., Gorwood, P., 2014b. Genetics of borderline personality disorder: Systematic review and proposal of an integrative model. Neurosci. Biobehav. Rev. 40C, 6-19. https://doi.org/10.1016/j.neubiorev.2014.01.003

Amad, A., Seidman, J., Draper, S.B., Bruchhage, M.M.K., Lowry, R.G., Wheeler, J., Robertson, A., Williams, S.C.R., Smith, M.S., 2017. Motor Learning Induces Plasticity in the Resting BrainDrumming Up a Connection. Cereb. Cortex 27, 2010-2021. https://doi.org/10.1093/cercor/bhw048

Amad, A., Seidman, J., Draper, S.B., Bruchhage, M.M.K., Lowry, R.G., Wheeler, J., Robertson, A., Williams, S.C.R., Smith, M.S., 2016. Motor Learning Induces Plasticity in the Resting BrainDrumming Up a Connection. Cereb. Cortex N. Y. N 1991. https://doi.org/10.1093/cercor/bhw048

Anticevic, A., Cole, M.W., Repovs, G., Murray, J.D., Brumbaugh, M.S., Winkler, A.M., Savic, A., Krystal, J.H., Pearlson, G.D., Glahn, D.C., 2014. Characterizing thalamo-cortical disturbances in schizophrenia and bipolar illness. Cereb. Cortex N. Y. N 1991 24, 3116-3130. https://doi.org/10.1093/cercor/bht165

Ashby, F.G., Turner, B.O., Horvitz, J.C., 2010. Cortical and basal ganglia contributions to habit learning and automaticity. Trends Cogn. Sci. 14, 208-215. https://doi.org/10.1016/j.tics.2010.02.001

Bellivier, F., Geoffroy, P.A., Scott, J., Schurhoff, F., Leboyer, M., Etain, B., 2013. Biomarkers of bipolar disorder: specific or shared with schizophrenia? Front. Biosci. Elite Ed. 5, 845-863.

Berk, M., 2009. Neuroprogression: pathways to progressive brain changes in bipolar disorder. Int. J. Neuropsychopharmacol. 12, 441-445. https://doi.org/10.1017/S1461145708009498

Berk, M, Brnabic, A., Dodd, S., Kelin, K., Tohen, M., Malhi, G.S., Berk, L., Conus, P., McGorry, P.D., 2011a. Does stage of illness impact treatment response in bipolar disorder? Empirical treatment data and their implication for the staging model and early intervention. Bipolar Disord. 13, 87-98. https://doi.org/10.1111/j.1399-5618.2011.00889.x

Berk, M., Kapczinski, F., Andreazza, A.C., Dean, O.M., Giorlando, F., Maes, M., Yücel, M., Gama, C.S., Dodd, S., Dean, B., Magalhães, P.V.S., Amminger, P., McGorry, P., Malhi, G.S., 2011 b. Pathways underlying neuroprogression in bipolar disorder: focus on inflammation, oxidative stress and neurotrophic factors. Neurosci. Biobehav. Rev. 35, 804-817. https://doi.org/10.1016/j.neubiorev.2010.10.001

Boehm, I., Geisler, D., King, J.A., Ritschel, F., Seidel, M., Deza Araujo, Y., Petermann, J., Lohmeier, H., Weiss, J., Walter, M., Roessner, V., Ehrlich, S., 2014. Increased resting state functional connectivity in the fronto-parietal and default mode network in anorexia nervosa. Front. Behav. Neurosci. 8, 346. https://doi.org/10.3389/fnbeh.2014.00346

Bora, E., Fornito, A., Yücel, M., Pantelis, C., 2010. Voxelwise meta-analysis of gray matter abnormalities in bipolar disorder. Biol. Psychiatry 67, 1097-1105. https://doi.org/10.1016/j.biopsych.2010.01.020 
Brady, R.O., Masters, G.A., Mathew, I.T., Margolis, A., Cohen, B.M., Öngür, D., Keshavan, M., 2016. State dependent cortico-amygdala circuit dysfunction in bipolar disorder. J. Affect. Disord. 201, 79-87. https://doi.org/10.1016/j.jad.2016.04.052

Brainstorm Consortium, Anttila, V., Bulik-Sullivan, B., Finucane, H.K., Walters, R.K., Bras, J., Duncan, L., Escott-Price, V., Falcone, G.J., Gormley, P., Malik, R., Patsopoulos, N.A., Ripke, S., Wei, Z., Yu, D., Lee, P.H., Turley, P., Grenier-Boley, B., Chouraki, V., Kamatani, Y., Berr, C., Letenneur, L., Hannequin, D., Amouyel, P., Boland, A., Deleuze, J.-F., Duron, E., Vardarajan, B.N., Reitz, C., Goate, A.M., Huentelman, M.J., Kamboh, M.I., Larson, E.B., Rogaeva, E., St George-Hyslop, P., Hakonarson, H., Kukull, W.A., Farrer, L.A., Barnes, L.L., Beach, T.G., Demirci, F.Y., Head, E., Hulette, C.M., Jicha, G.A., Kauwe, J.S.K., Kaye, J.A., Leverenz, J.B., Levey, A.I., Lieberman, A.P., Pankratz, V.S., Poon, W.W., Quinn, J.F., Saykin, A.J., Schneider, L.S., Smith, A.G., Sonnen, J.A., Stern, R.A., Van Deerlin, V.M., Van Eldik, L.J., Harold, D., Russo, G., Rubinsztein, D.C., Bayer, A., Tsolaki, M., Proitsi, P., Fox, N.C., Hampel, H., Owen, M.J., Mead, S., Passmore, P., Morgan, K., Nöthen, M.M., Rossor, M., Lupton, M.K., Hoffmann, P., Kornhuber, J., Lawlor, B., McQuillin, A., Al-Chalabi, A., Bis, J.C., Ruiz, A., Boada, M., Seshadri, S., Beiser, A., Rice, K., van der Lee, S.J., De Jager, P.L., Geschwind, D.H., Riemenschneider, M., Riedel-Heller, S., Rotter, J.I., Ransmayr, G., Hyman, B.T., Cruchaga, C., Alegret, M., Winsvold, B., Palta, P., Farh, K.-H., Cuenca-Leon, E., Furlotte, N., Kurth, T., Ligthart, L., Terwindt, G.M., Freilinger, T., Ran, C., Gordon, S.D., Borck, G., Adams, H.H.H., Lehtimäki, T., Wedenoja, J., Buring, J.E., Schürks, M., Hrafnsdottir, M., Hottenga, J.-J., Penninx, B., Artto, V., Kaunisto, M., Vepsäläinen, S., Martin, N.G., Montgomery, G.W., Kurki, M.I., Hämäläinen, E., Huang, H., Huang, J., Sandor, C., Webber, C., Muller-Myhsok, B., Schreiber, S., Salomaa, V., Loehrer, E., Göbel, H., Macaya, A., Pozo-Rosich, P., Hansen, T., Werge, T., Kaprio, J., Metspalu, A., Kubisch, C., Ferrari, M.D., Belin, A.C., van den Maagdenberg, A.M.J.M., Zwart, J.-A., Boomsma, D., Eriksson, N., Olesen, J., Chasman, D.I., Nyholt, D.R., Avbersek, A., Baum, L., Berkovic, S., Bradfield, J., Buono, R., Catarino, C.B., Cossette, P., De Jonghe, P., Depondt, C., Dlugos, D., Ferraro, T.N., French, J., Hjalgrim, H., Jamnadas-Khoda, J., Kälviäinen, R., Kunz, W.S., Lerche, H., Leu, C., Lindhout, D., Lo, W., Lowenstein, D., McCormack, M., Møller, R.S., Molloy, A., Ng, P.-W., Oliver, K., Privitera, M., Radtke, R., Ruppert, A.-K., Sander, T., Schachter, S., Schankin, C., Scheffer, I., Schoch, S., Sisodiya, S.M., Smith, P., Sperling, M., Striano, P., Surges, R., Thomas, G.N., Visscher, F., Whelan, C.D., Zara, F., Heinzen, E.L., Marson, A., Becker, F., Stroink, H., Zimprich, F., Gasser, T., Gibbs, R., Heutink, P., Martinez, M., Morris, H.R., Sharma, M., Ryten, M., Mok, K.Y., Pulit, S., Bevan, S., Holliday, E., Attia, J., Battey, T., Boncoraglio, G., Thijs, V., Chen, W.M., Mitchell, B., Rothwell, P., Sharma, P., Sudlow, C., Vicente, A., Markus, H., Kourkoulis, C., Pera, J., Raffeld, M., Silliman, S., Boraska Perica, V., Thornton, L.M., Huckins, L.M., William Rayner, N., Lewis, C.M., Gratacos, M., Rybakowski, F., Keski-Rahkonen, A., Raevuori, A., Hudson, J.I., Reichborn-Kjennerud, T., Monteleone, P., Karwautz, A., Mannik, K., Baker, J.H., O’Toole, J.K., Trace, S.E., Davis, O.S.P., Helder, S.G., Ehrlich, S., Herpertz-Dahlmann, B., Danner, U.N., van Elburg, A.A., Clementi, M., Forzan, M., Docampo, E., Lissowska, J., Hauser, J., Tortorella, A., Maj, M., Gonidakis, F., Tziouvas, K., Papezova, H., Yilmaz, Z., Wagner, G., Cohen-Woods, S., Herms, S., Julià, A., Rabionet, R., Dick, D.M., Ripatti, S., Andreassen, O.A., Espeseth, T., Lundervold, A.J., Steen, V.M., Pinto, D., Scherer, S.W., Aschauer, H., Schosser, A., Alfredsson, L., Padyukov, L., Halmi, K.A., Mitchell, J., Strober, M., Bergen, A.W., Kaye, W., Szatkiewicz, J.P., Cormand, B., Ramos-Quiroga, J.A., Sánchez-Mora, C., Ribasés, M., Casas, M., Hervas, A., Arranz, M.J., Haavik, J., Zayats, T., Johansson, S., Williams, N., Dempfle, A., Rothenberger, A., Kuntsi, J., Oades, R.D., Banaschewski, T., Franke, B., Buitelaar, J.K., Arias Vasquez, A., Doyle, A.E., Reif, A., Lesch, K.-P., Freitag, C., Rivero, O., Palmason, H., Romanos, M., Langley, K., Rietschel, M., Witt, S.H., Dalsgaard, S., Børglum, A.D., Waldman, I., Wilmot, B., Molly, N., Bau, C.H.D., Crosbie, J., Schachar, R., Loo, S.K., McGough, J.J., Grevet, E.H., Medland, S.E., Robinson, E., Weiss, L.A., Bacchelli, E., Bailey, A., Bal, V., Battaglia, A., Betancur, C., Bolton, P., Cantor, R., Celestino-Soper, P., Dawson, G., De Rubeis, S., Duque, F., Green, A., Klauck, S.M., Leboyer, M., Levitt, P., Maestrini, E., Mane, S., De-Luca, D.M.-, Parr, 
J., Regan, R., Reichenberg, A., Sandin, S., Vorstman, J., Wassink, T., Wijsman, E., Cook, E., Santangelo, S., Delorme, R., Rogé, B., Magalhaes, T., Arking, D., Schulze, T.G., Thompson, R.C., Strohmaier, J., Matthews, K., Melle, I., Morris, D., Blackwood, D., Mclntosh, A., Bergen, S.E., Schalling, M., Jamain, S., Maaser, A., Fischer, S.B., Reinbold, C.S., Fullerton, J.M., Guzman-Parra, J., Mayoral, F., Schofield, P.R., Cichon, S., Mühleisen, T.W., Degenhardt, F., Schumacher, J., Bauer, M., Mitchell, P.B., Gershon, E.S., Rice, J., Potash, J.B., Zandi, P.P., Craddock, N., Ferrier, I.N., Alda, M., Rouleau, G.A., Turecki, G., Ophoff, R., Pato, C., Anjorin, A., Stahl, E., Leber, M., Czerski, P.M., Cruceanu, C., Jones, I.R., Posthuma, D., Andlauer, T.F.M., Forstner, A.J., Streit, F., Baune, B.T., Air, T., Sinnamon, G., Wray, N.R., Maclntyre, D.J., Porteous, D., Homuth, G., Rivera, M., Grove, J., Middeldorp, C.M., Hickie, I., Pergadia, M., Mehta, D., Smit, J.H., Jansen, R., de Geus, E., Dunn, E., Li, Q.S., Nauck, M., Schoevers, R.A., Beekman, A.T., Knowles, J.A., Viktorin, A., Arnold, P., Barr, C.L., Bedoya-Berrio, G., Bienvenu, O.J., Brentani, H., Burton, C., Camarena, B., Cappi, C., Cath, D., Cavallini, M., Cusi, D., Darrow, S., Denys, D., Derks, E.M., Dietrich, A., Fernandez, T., Figee, M., Freimer, N., Gerber, G., Grados, M., Greenberg, E., Hanna, G.L., Hartmann, A., Hirschtritt, M.E., Hoekstra, P.J., Huang, A., Huyser, C., Illmann, C., Jenike, M., Kuperman, S., Leventhal, B., Lochner, C., Lyon, G.J., Macciardi, F., Madruga-Garrido, M., Malaty, I.A., Maras, A., McGrath, L., Miguel, E.C., Mir, P., Nestadt, G., Nicolini, H., Okun, M.S., Pakstis, A., Paschou, P., Piacentini, J., Pittenger, C., Plessen, K., Ramensky, V., Ramos, E.M., Reus, V., Richter, M.A., Riddle, M.A., Robertson, M.M., Roessner, V., Rosário, M., Samuels, J.F., Sandor, P., Stein, D.J., Tsetsos, F., Van Nieuwerburgh, F., Weatherall, S., Wendland, J.R., Wolanczyk, T., Worbe, Y., Zai, G., Goes, F.S., Mclaughlin, N., Nestadt, P.S., Grabe, H.-J., Depienne, C., Konkashbaev, A., Lanzagorta, N., Valencia-Duarte, A., Bramon, E., Buccola, N., Cahn, W., Cairns, M., Chong, S.A., Cohen, D., Crespo-Facorro, B., Crowley, J., Davidson, M., DeLisi, L., Dinan, T., Donohoe, G., Drapeau, E., Duan, J., Haan, L., Hougaard, D., Karachanak-Yankova, S., Khrunin, A., Klovins, J., Kučinskas, V., Lee Chee Keong, J., Limborska, S., Loughland, C., Lönnqvist, J., Maher, B., Mattheisen, M., McDonald, C., Murphy, K.C., Nenadic, I., van Os, J., Pantelis, C., Pato, M., Petryshen, T., Quested, D., Roussos, P., Sanders, A.R., Schall, U., Schwab, S.G., Sim, K., So, H.-C., Stögmann, E., Subramaniam, M., Toncheva, D., Waddington, J., Walters, J., Weiser, M., Cheng, W., Cloninger, R., Curtis, D., Gejman, P.V., Henskens, F., Mattingsdal, M., Oh, S.-Y., Scott, R., Webb, B., Breen, G., Churchhouse, C., Bulik, C.M., Daly, M., Dichgans, M., Faraone, S.V., Guerreiro, R., Holmans, P., Kendler, K.S., Koeleman, B., Mathews, C.A., Price, A., Scharf, J., Sklar, P., Williams, J., Wood, N.W., Cotsapas, C., Palotie, A., Smoller, J.W., Sullivan, P., Rosand, J., Corvin, A., Neale, B.M., 2018. Analysis of shared heritability in common disorders of the brain. Science 360. https://doi.org/10.1126/science.aap8757

Bremner, J.D., 2006. Traumatic stress: effects on the brain. Dialogues Clin. Neurosci. 8, 445-461.

Brennand, K.J., Simone, A., Jou, J., Gelboin-Burkhart, C., Tran, N., Sangar, S., Li, Y., Mu, Y., Chen, G., Yu, D., McCarthy, S., Sebat, J., Gage, F.H., 2011. Modelling schizophrenia using human induced pluripotent stem cells. Nature 473, 221-225. https://doi.org/10.1038/nature09915

Buckholtz, J.W., Meyer-Lindenberg, A., 2012. Psychopathology and the human connectome: toward a transdiagnostic model of risk for mental illness. Neuron 74, 990-1004. https://doi.org/10.1016/j.neuron.2012.06.002

Buckner, R.L., Vincent, J.L., 2007. Unrest at rest: default activity and spontaneous network correlations. Neurolmage 37, 1091-1096. https://doi.org/10.1016/j.neuroimage.2007.01.010

Buka, S.L., 2008. Psychiatric Epidemiology: Reducing the Global Burden of Mental Illness. Am. J. Epidemiol. 168, 977-979. https://doi.org/10.1093/aje/kwn298

Bullmore, E., Sporns, O., 2012. The economy of brain network organization. Nat. Rev. Neurosci. 13, 336-349. https://doi.org/10.1038/nrn3214

Buonaguro, E.F., lasevoli, F., Marmo, F., Eramo, A., Latte, G., Avagliano, C., Tomasetti, C., de Bartolomeis, A., 2017. Re-arrangements of gene transcripts at glutamatergic synapses after prolonged treatments with antipsychotics: A putative link with synaptic remodeling. Prog. 
$\begin{array}{llll}\text { Neuropsychopharmacol. } & \text { Biol. }\end{array}$ https://doi.org/10.1016/j.pnpbp.2017.02.012

Caligiore, D., Pezzulo, G., Baldassarre, G., Bostan, A.C., Strick, P.L., Doya, K., Helmich, R.C., Dirkx, M., Houk, J., Jörntell, H., Lago-Rodriguez, A., Galea, J.M., Miall, R.C., Popa, T., Kishore, A., Verschure, P.F.M.J., Zucca, R., Herreros, I., 2017. Consensus Paper: Towards a Systems-Level View of Cerebellar Function: the Interplay Between Cerebellum, Basal Ganglia, and Cortex. Cerebellum Lond. Engl. 16, 203-229. https://doi.org/10.1007/s12311-016-0763-3

Cerliani, L., Mennes, M., Thomas, R.M., Di Martino, A., Thioux, M., Keysers, C., 2015. Increased Functional Connectivity Between Subcortical and Cortical Resting-State Networks in Autism Spectrum Disorder. JAMA Psychiatry 72, 767-777.

Cerullo, M.A., Fleck, D.E., Eliassen, J.C., Smith, M.S., DelBello, M.P., Adler, C.M., Strakowski, S.M., 2012. A longitudinal functional connectivity analysis of the amygdala in bipolar I disorder across mood states. Bipolar Disord. 14, 175-184. https://doi.org/10.1111/j.13995618.2012.01002.x

Chan, R.C.K., Di, X., McAlonan, G.M., Gong, Q., 2011. Brain anatomical abnormalities in high-risk individuals, first-episode, and chronic schizophrenia: an activation likelihood estimation meta-analysis of illness progression. Schizophr. Bull. 37, 177-188. https://doi.org/10.1093/schbul/sbp073

Chialvo, D.R., 2010. Emergent complex neural dynamics. Nat. Phys. 6, 744-750. https://doi.org/10.1038/nphys1803

Colibazzi, T., Wexler, B.E., Bansal, R., Hao, X., Liu, J., Sanchez-Peña, J., Corcoran, C., Lieberman, J.A., Peterson, B.S., 2013. Anatomical abnormalities in gray and white matter of the cortical surface in persons with schizophrenia. PloS One 8, e55783. https://doi.org/10.1371/journal.pone.0055783

Cramer, S.C., Sur, M., Dobkin, B.H., O’Brien, C., Sanger, T.D., Trojanowski, J.Q., Rumsey, J.M., Hicks, R., Cameron, J., Chen, D., Chen, W.G., Cohen, L.G., deCharms, C., Duffy, C.J., Eden, G.F., Fetz, E.E., Filart, R., Freund, M., Grant, S.J., Haber, S., Kalivas, P.W., Kolb, B., Kramer, A.F., Lynch, M., Mayberg, H.S., McQuillen, P.S., Nitkin, R., Pascual-Leone, A., Reuter-Lorenz, P., Schiff, N., Sharma, A., Shekim, L., Stryker, M., Sullivan, E.V., Vinogradov, S., 2011. Harnessing neuroplasticity for clinical applications. Brain 134, 1591-1609. https://doi.org/10.1093/brain/awr039

Crossley, N.A., Mechelli, A., Ginestet, C., Rubinov, M., Bullmore, E.T., McGuire, P., 2016. Altered Hub Functioning and Compensatory Activations in the Connectome: A Meta-Analysis of Functional Neuroimaging Studies in Schizophrenia. Schizophr. Bull. 42, 434-442. https://doi.org/10.1093/schbul/sbv146

Crossley, N.A., Mechelli, A., Scott, J., Carletti, F., Fox, P.T., McGuire, P., Bullmore, E.T., 2014. The hubs of the human connectome are generally implicated in the anatomy of brain disorders. Brain J. Neurol. 137, 2382-2395. https://doi.org/10.1093/brain/awu132

Davis, J., Moylan, S., Harvey, B.H., Maes, M., Berk, M., 2014. Neuroprogression in schizophrenia: Pathways underpinning clinical staging and therapeutic corollaries. Aust. N. Z. J. Psychiatry 48, 512-529. https://doi.org/10.1177/0004867414533012

de Kloet, E.R., Joëls, M., Holsboer, F., 2005. Stress and the brain: from adaptation to disease. Nat. Rev. Neurosci. 6, 463-475. https://doi.org/10.1038/nrn1683

de Wit, S.J., Alonso, P., Schweren, L., Mataix-Cols, D., Lochner, C., Menchón, J.M., Stein, D.J., Fouche, J.-P., Soriano-Mas, C., Sato, J.R., Hoexter, M.Q., Denys, D., Nakamae, T., Nishida, S., Kwon, J.S., Jang, J.H., Busatto, G.F., Cardoner, N., Cath, D.C., Fukui, K., Jung, W.H., Kim, S.N., Miguel, E.C., Narumoto, J., Phillips, M.L., Pujol, J., Remijnse, P.L., Sakai, Y., Shin, N.Y., Yamada, K., Veltman, D.J., van den Heuvel, O.A., 2014. Multicenter Voxel-Based Morphometry MegaAnalysis of Structural Brain Scans in Obsessive-Compulsive Disorder. Am. J. Psychiatry 171, 340-349. https://doi.org/10.1176/appi.ajp.2013.13040574

Dondé, C., Amad, A., Nieto, I., Brunoni, A.R., Neufeld, N.H., Bellivier, F., Poulet, E., Geoffroy, P.-A., 2017. Transcranial direct-current stimulation (tDCS) for bipolar depression: A systematic 
review and meta-analysis. Prog. Neuropsychopharmacol. Biol. Psychiatry 78, 123-131. https://doi.org/10.1016/j.pnpbp.2017.05.021

Dong, D., Wang, Y., Chang, X., Luo, C., Yao, D., 2018. Dysfunction of Large-Scale Brain Networks in Schizophrenia: A Meta-analysis of Resting-State Functional Connectivity. Schizophr. Bull. 44, 168-181. https://doi.org/10.1093/schbul/sbx034

Dong, Q., Welsh, R.C., Chenevert, T.L., Carlos, R.C., Maly-Sundgren, P., Gomez-Hassan, D.M., Mukherji, S.K., 2004. Clinical applications of diffusion tensor imaging. J. Magn. Reson. Imaging 19, 6-18. https://doi.org/10.1002/jmri.10424

Downar, J., Blumberger, D.M., Daskalakis, Z.J., 2016. The Neural Crossroads of Psychiatric Illness: An Emerging Target for Brain Stimulation. Trends Cogn. Sci. 20, 107-120. https://doi.org/10.1016/j.tics.2015.10.007

Draganski, B., Gaser, C., Busch, V., Schuierer, G., Bogdahn, U., May, A., 2004. Neuroplasticity: changes in grey matter induced by training. Nature 427, 311-312. https://doi.org/10.1038/427311a

Driemeyer, J., Boyke, J., Gaser, C., Büchel, C., May, A., 2008. Changes in Gray Matter Induced by Learning-Revisited. PLoS ONE 3, e2669. https://doi.org/10.1371/journal.pone.0002669

Eack, S.M., Hogarty, G.E., Cho, R.Y., Prasad, K.M.R., Greenwald, D.P., Hogarty, S.S., Keshavan, M.S., 2010. Neuroprotective effects of cognitive enhancement therapy against gray matter loss in early schizophrenia: results from a 2-year randomized controlled trial. Arch. Gen. Psychiatry 67, 674-682. https://doi.org/10.1001/archgenpsychiatry.2010.63

Eker, C., Gonul, A.S., 2010. Volumetric MRI studies of the hippocampus in major depressive disorder: Meanings of inconsistency and directions for future research. World J. Biol. Psychiatry Off. J. World Fed. Soc. Biol. Psychiatry 11, 19-35. https://doi.org/10.1080/15622970902737998

Expert, P., Lambiotte, R., Chialvo, D.R., Christensen, K., Jensen, H.J., Sharp, D.J., Turkheimer, F., 2011. Self-similar correlation function in brain resting-state functional magnetic resonance imaging. J. R. Soc. Interface 8, 472-479. https://doi.org/10.1098/rsif.2010.0416

Favre, P., Baciu, M., Pichat, C., Bougerol, T., Polosan, M., 2014. fMRI evidence for abnormal restingstate functional connectivity in euthymic bipolar patients. J. Affect. Disord. 165, 182-189. https://doi.org/10.1016/j.jad.2014.04.054

Fornito, A., Bullmore, E.T., 2015. Reconciling abnormalities of brain network structure and function in schizophrenia. Curr. Opin. Neurobiol. 30, 44-50. https://doi.org/10.1016/j.conb.2014.08.006

Fornito, A., Harrison, B.J., Goodby, E., Dean, A., Ooi, C., Nathan, P.J., Lennox, B.R., Jones, P.B., Suckling, J., Bullmore, E.T., 2013. Functional dysconnectivity of corticostriatal circuitry as a risk phenotype for psychosis. JAMA Psychiatry 70, 1143-1151. https://doi.org/10.1001/jamapsychiatry.2013.1976

Fovet, T., Orlov, N., Dyck, M., Allen, P., Mathiak, K., Jardri, R., 2016. Translating Neurocognitive Models of Auditory-Verbal Hallucinations into Therapy: Using Real-time fMRI-Neurofeedback to Treat Voices. Front. Psychiatry 7, 103. https://doi.org/10.3389/fpsyt.2016.00103

Fox, M.D., Raichle, M.E., 2007. Spontaneous fluctuations in brain activity observed with functional magnetic resonance imaging. Nat. Rev. Neurosci. 8, 700-711. https://doi.org/10.1038/nrn2201

Friston, K.J., 1998. The disconnection hypothesis. Schizophr. Res. 30, 115-125. https://doi.org/16/S0920-9964(97)00140-0

Froemke, R.C., 2015. Plasticity of Cortical Excitatory-Inhibitory Balance. Annu. Rev. Neurosci. 38, 195219. https://doi.org/10.1146/annurev-neuro-071714-034002

Furman, D.J., Hamilton, J.P., Gotlib, I.H., 2011. Frontostriatal functional connectivity in major depressive disorder. Biol. Mood Anxiety Disord. 1, 11. https://doi.org/10.1186/2045-5380-111

Gillan, C.M., Robbins, T.W., Sahakian, B.J., van den Heuvel, O.A., van Wingen, G., 2016. The role of habit in compulsivity. Eur. Neuropsychopharmacol. 26, 828-840. https://doi.org/10.1016/j.euroneuro.2015.12.033 
Goldapple, K., Segal, Z., Garson, C., Lau, M., Bieling, P., Kennedy, S., Mayberg, H., 2004. Modulation of cortical-limbic pathways in major depression: treatment-specific effects of cognitive behavior therapy. Arch. Gen. Psychiatry 61, 34-41. https://doi.org/10.1001/archpsyc.61.1.34

Goodkind, M., Eickhoff, S.B., Oathes, D.J., Jiang, Y., Chang, A., Jones-Hagata, L.B., Ortega, B.N., Zaiko, Y.V., Roach, E.L., Korgaonkar, M.S., Grieve, S.M., Galatzer-Levy, I., Fox, P.T., Etkin, A., 2015. Identification of a common neurobiological substrate for mental illness. JAMA Psychiatry 72, 305-315. https://doi.org/10.1001/jamapsychiatry.2014.2206

Goya-Maldonado, R., Brodmann, K., Keil, M., Trost, S., Dechent, P., Gruber, O., 2016. Differentiating unipolar and bipolar depression by alterations in large-scale brain networks. Hum. Brain Mapp. 37, 808-818. https://doi.org/10.1002/hbm.23070

Grande, I., Berk, M., Birmaher, B., Vieta, E., 2016. Bipolar disorder. The Lancet 387, $1561-1572$. https://doi.org/10.1016/S0140-6736(15)00241-X

Graybiel, A.M., 2008. Habits, rituals, and the evaluative brain. Annu Rev Neurosci 31, 359-387.

Green, C.S., Bavelier, D., 2008. Exercising Your Brain: A Review of Human Brain Plasticity and Training-Induced Learning. Psychol. Aging 23, 692-701. https://doi.org/10.1037/a0014345

Greicius, M.D., Flores, B.H., Menon, V., Glover, G.H., Solvason, H.B., Kenna, H., Reiss, A.L., Schatzberg, A.F., 2007. Resting-state functional connectivity in major depression: abnormally increased contributions from subgenual cingulate cortex and thalamus. Biol. Psychiatry 62, 429-437. https://doi.org/10.1016/j.biopsych.2006.09.020

Greicius, M.D., Krasnow, B., Reiss, A.L., Menon, V., 2003. Functional connectivity in the resting brain: a network analysis of the default mode hypothesis. Proc. Natl. Acad. Sci. U. S. A. 100, 253258. https://doi.org/10.1073/pnas.0135058100

Griesinger, W., 1867. Mental Pathology and Therapeutics. The New Sydenham Society, London Hardcover, English Translation., The New Sydenham Society, London Hardcover, English Translation. 207.

Guerra-Carrillo, B., Mackey, A.P., Bunge, S.A., 2014. Resting-state fMRI: a window into human brain plasticity. The Neuroscientist4 20, 522-533. https://doi.org/10.1177/1073858414524442

Gur, R.E., Maany, V., Mozley, P.D., Swanson, C., Bilker, W., Gur, R.C., 1998. Subcortical MRI volumes in neuroleptic-naive and treated patients with schizophrenia. Am. J. Psychiatry 155, 17111717. https://doi.org/10.1176/ajp.155.12.1711

Haijma, S.V., Van Haren, N., Cahn, W., Koolschijn, P.C.M.P., Hulshoff Pol, H.E., Kahn, R.S., 2013. Brain volumes in schizophrenia: a meta-analysis in over 18000 subjects. Schizophr. Bull. 39, 11291138. https://doi.org/10.1093/schbul/sbs118

Hardan, A.Y., Muddasani, S., Vemulapalli, M., Keshavan, M.S., Minshew, N.J., 2006. An MRI Study of Increased Cortical Thickness in Autism. Am. J. Psychiatry 163, 1290-1292. https://doi.org/10.1176/ajp.2006.163.7.1290

Hoffman, R.E., Fernandez, T., Pittman, B., Hampson, M., 2011. Elevated functional connectivity along a corticostriatal loop and the mechanism of auditory/verbal hallucinations in patients with schizophrenia. Biol. Psychiatry 69, 407-414. https://doi.org/10.1016/j.biopsych.2010.09.050

Hutto, D.D., 1999. Cognition without Representation?, in: Riegler, A., Peschl, M., von Stein, A. (Eds.), Understanding Representation in the Cognitive Sciences. Springer US, Boston, MA, pp. 5774. https://doi.org/10.1007/978-0-585-29605-0_7

Johansen-Berg, H., Rushworth, M.F.S., 2009. Using diffusion imaging to study human connectional $\begin{array}{lllll}\text { anatomy. Annu. } & \text { Rev. }\end{array}$ https://doi.org/10.1146/annurev.neuro.051508.135735

Kapczinski, F., Streb, L.G., Kapczinski, F., Streb, L.G., 2014. Neuroprogression and staging in psychiatry: historical considerations. Rev. Bras. Psiquiatr. 36, 187-188. https://doi.org/10.1590/1516-4446-2014-3605

Kapczinski, F., Vieta, E., Andreazza, A.C., Frey, B.N., Gomes, F.A., Tramontina, J., Kauer-Sant'anna, M., Grassi-Oliveira, R., Post, R.M., 2008. Allostatic load in bipolar disorder: implications for pathophysiology and treatment. Neurosci. Biobehav. Rev. 32, 675-692. https://doi.org/10.1016/j.neubiorev.2007.10.005 
Kim, J.J., Lee, M.C., Kim, J., Kim, I.Y., Kim, S.I., Han, M.H., Chang, K.H., Kwon, J.S., 2001. Grey matter abnormalities in obsessive-compulsive disorder: statistical parametric mapping of segmented magnetic resonance images. Br. J. Psychiatry J. Ment. Sci. 179, 330-334.

Kinouchi, O., Copelli, M., 2006. Optimal dynamical range of excitable networks at criticality. Nat. Phys. 2, 348-351. https://doi.org/10.1038/nphys289

Koob, G.F., Moal, M.L., 2005. Plasticity of reward neurocircuitry and the "dark side" of drug addiction [WWW Document]. Nat. Neurosci. https://doi.org/10.1038/nn1105-1442

Krueger, R.F., Eaton, N.R., 2015. Transdiagnostic factors of mental disorders. World Psychiatry 14, 27-29. https://doi.org/10.1002/wps.20175

Krystal, J.H., State, M.W., 2014. Psychiatric disorders: diagnosis to therapy. Cell 157, 201-214. https://doi.org/10.1016/j.cell.2014.02.042

Langen, M., Durston, S., Kas, M.J., van Engeland, H., Staal, W.G., 2011. The neurobiology of repetitive behavior:... and men. Neurosci. Biobehav. Rev. 35, 356-365.

Lewis, C.M., Baldassarre, A., Committeri, G., Romani, G.L., Corbetta, M., 2009. Learning sculpts the spontaneous activity of the resting human brain. Proc. Natl. Acad. Sci. 106, 17558-17563. https://doi.org/10.1073/pnas.0902455106

Li, M., Chen, Z., Deng, W., He, Z., Wang, Q., Jiang, L., Ma, X., Wang, Y., Chua, S.E., Cheung, C., McAlonan, G.M., Sham, P.C., Collier, D.A., Gong, Q., Li, T., 2012. Volume increases in putamen associated with positive symptom reduction in previously drug-naive schizophrenia after 6 weeks antipsychotic treatment. Psychol. Med. 42, 1475-1483. https://doi.org/10.1017/S0033291711002157

Li, T., Wang, Q., Zhang, J., Rolls, E.T., Yang, W., Palaniyappan, L., Zhang, L., Cheng, W., Yao, Y., Liu, Zhaowen, Gong, X., Luo, Q., Tang, Y., Crow, T.J., Broome, M.R., Xu, K., Li, C., Wang, J., Liu, Zhening, Lu, G., Wang, F., Feng, J., 2017. Brain-Wide Analysis of Functional Connectivity in First-Episode and Chronic Stages of Schizophrenia. Schizophr. Bull. 43, 436-448. https://doi.org/10.1093/schbul/sbw099

Linden, D.E.J., 2006. How psychotherapy changes the brain--the contribution of functional neuroimaging. Mol. Psychiatry 11, 528-538. https://doi.org/10.1038/sj.mp.4001816

Lord, L.-D., Allen, P., Expert, P., Howes, O., Broome, M., Lambiotte, R., Fusar-Poli, P., Valli, I., McGuire, P., Turkheimer, F.E., 2012. Functional brain networks before the onset of psychosis: A prospective fMRI study with graph theoretical analysis. Neurolmage Clin. 1, 91-98. https://doi.org/10.1016/j.nicl.2012.09.008

Lord, L.-D., Allen, P., Expert, P., Howes, O., Lambiotte, R., McGuire, P., Bose, S.K., Hyde, S., Turkheimer, F.E., 2011. Characterization of the anterior cingulate's role in the at-risk mental state using graph theory. Neurolmage 56, 1531-1539. https://doi.org/10.1016/j.neuroimage.2011.02.012

Lord, L.-D., Stevner, A.B., Deco, G., Kringelbach, M.L., 2017. Understanding principles of integration and segregation using whole-brain computational connectomics: implications for neuropsychiatric disorders. Philos. Transact. A Math. Phys. Eng. Sci. 375. https://doi.org/10.1098/rsta.2016.0283

Luber, B.M., Davis, S., Bernhardt, E., Neacsiu, A., Kwapil, L., Lisanby, S.H., Strauman, T.J., 2017. Using neuroimaging to individualize TMS treatment for depression: Toward a new paradigm for imaging-guided intervention. Neurolmage 148, 1-7. https://doi.org/10.1016/j.neuroimage.2016.12.083

Lythe, K.E., Moll, J., Gethin, J.A., Workman, C.I., Green, S., Lambon Ralph, M.A., Deakin, J.F.W., Zahn, R., 2015. Self-blame-Selective Hyperconnectivity Between Anterior Temporal and Subgenual Cortices and Prediction of Recurrent Depressive Episodes. JAMA Psychiatry 72, 1119-1126. https://doi.org/10.1001/jamapsychiatry.2015.1813

Maes, M., Nowak, G., Caso, J.R., Leza, J.C., Song, C., Kubera, M., Klein, H., Galecki, P., Noto, C., Glaab, E., Balling, R., Berk, M., 2016. Toward Omics-Based, Systems Biomedicine, and Path and Drug Discovery Methodologies for Depression-Inflammation Research. Mol. Neurobiol. 53, 29272935. https://doi.org/10.1007/s12035-015-9183-5 
Maguire, E.A., Gadian, D.G., Johnsrude, I.S., Good, C.D., Ashburner, J., Frackowiak, R.S., Frith, C.D., 2000. Navigation-related structural change in the hippocampi of taxi drivers. Proc. Natl. Acad. Sci. U. S. A. 97, 4398-4403. https://doi.org/10.1073/pnas.070039597

McGorry, P., Keshavan, M., Goldstone, S., Amminger, P., Allott, K., Berk, M., Lavoie, S., Pantelis, C., Yung, A., Wood, S., Hickie, I., 2014. Biomarkers and clinical staging in psychiatry. World Psychiatry Off. J. World Psychiatr. Assoc. WPA 13, 211-223. https://doi.org/10.1002/wps.20144

McGorry, P.D., Hickie, I.B., Yung, A.R., Pantelis, C., Jackson, H.J., 2006. Clinical staging of psychiatric disorders: a heuristic framework for choosing earlier, safer and more effective interventions. Aust. N. Z. J. Psychiatry 40, 616-622. https://doi.org/10.1111/j.1440-1614.2006.01860.x

McGorry, P.D., Nelson, B., Goldstone, S., Yung, A.R., 2010. Clinical staging: a heuristic and practical strategy for new research and better health and social outcomes for psychotic and related mood disorders. Can. J. Psychiatry Rev. Can. Psychiatr. 55, 486-497.

McHugh, P.R., 2005. Striving for Coherence: Psychiatry's Efforts Over Classification. JAMA 293, 25262528. https://doi.org/10.1001/jama.293.20.2526

Merzenich, M.M., Van Vleet, T.M., Nahum, M., 2014. Brain plasticity-based therapeutics. Front. Hum. Neurosci. 8. https://doi.org/10.3389/fnhum.2014.00385

Millan, M.J., Andrieux, A., Bartzokis, G., Cadenhead, K., Dazzan, P., Fusar-Poli, P., Gallinat, J., Giedd, J., Grayson, D.R., Heinrichs, M., Kahn, R., Krebs, M.-O., Leboyer, M., Lewis, D., Marin, O., Marin, P., Meyer-Lindenberg, A., McGorry, P., McGuire, P., Owen, M.J., Patterson, P., Sawa, A., Spedding, M., Uhlhaas, P., Vaccarino, F., Wahlestedt, C., Weinberger, D., 2016. Altering the course of schizophrenia: progress and perspectives. Nat. Rev. Drug Discov. 15, 485-515. https://doi.org/10.1038/nrd.2016.28

Moylan, S., Maes, M., Wray, N.R., Berk, M., 2013. The neuroprogressive nature of major depressive disorder: pathways to disease evolution and resistance, and therapeutic implications. Mol. Psychiatry 18, 595-606. https://doi.org/10.1038/mp.2012.33

Munkholm, K., Vinberg, M., Kessing, L.V., 2016. Peripheral blood brain-derived neurotrophic factor in bipolar disorder: a comprehensive systematic review and meta-analysis. Mol. Psychiatry 21, 216-228. https://doi.org/10.1038/mp.2015.54

Oertel-Knöchel, V., Knöchel, C., Matura, S., Rotarska-Jagiela, A., Magerkurth, J., Prvulovic, D., Haenschel, C., Hampel, H., Linden, D.E.J., 2012. Cortical-basal ganglia imbalance in schizophrenia patients and unaffected first-degree relatives. Schizophr. Res. 138, 120-127. https://doi.org/10.1016/j.schres.2012.02.029

Palaniyappan, L., 2017. Progressive cortical reorganisation: A framework for investigating structural changes in schizophrenia. Neurosci. Biobehav. Rev. 79, 1-13. https://doi.org/10.1016/j.neubiorev.2017.04.028

Pascual-Leone, A., Amedi, A., Fregni, F., Merabet, L.B., 2005. The Plastic Human Brain Cortex. Annu. Rev. Neurosci. 28, 377-401. https://doi.org/10.1146/annurev.neuro.27.070203.144216

Pol, H., E, H., Kahn, R.S., 2008. What Happens After the First Episode? A Review of Progressive Brain Changes in Chronically III Patients With Schizophrenia. Schizophr. Bull. 34, 354-366. https://doi.org/10.1093/schbul/sbm168

Post, R.M., 2007. Kindling and sensitization as models for affective episode recurrence, cyclicity, and tolerance phenomena. Neurosci. Biobehav. Rev. 31, 858-873. https://doi.org/10.1016/j.neubiorev.2007.04.003

Post, R.M., 1992. Transduction of psychosocial stress into the neurobiology of recurrent affective disorder. Am. J. Psychiatry 149, 999-1010. https://doi.org/10.1176/ajp.149.8.999

Radua, J., Mataix-Cols, D., 2009. Voxel-wise meta-analysis of grey matter changes in obsessivecompulsive disorder. Br. J. Psychiatry J. Ment. Sci. 195, 393-402. https://doi.org/10.1192/bjp.bp.108.055046

Radua, J., van den Heuvel, O.A., Surguladze, S., Mataix-Cols, D., 2010. Meta-analytical comparison of voxel-based morphometry studies in obsessive-compulsive disorder vs other anxiety 
$\begin{array}{lllll}\text { disorders. } & \text { Grch. }\end{array}$ https://doi.org/10.1001/archgenpsychiatry.2010.70

Rief, W., Barsky, A.J., Bingel, U., Doering, B.K., Schwarting, R., Wöhr, M., Schweiger, U., 2016. Rethinking psychopharmacotherapy: The role of treatment context and brain plasticity in antidepressant and antipsychotic interventions. Neurosci. Biobehav. Rev. 60, 51-64. https://doi.org/10.1016/j.neubiorev.2015.11.008

Rotge, J.-Y., Langbour, N., Guehl, D., Bioulac, B., Jaafari, N., Allard, M., Aouizerate, B., Burbaud, P., 2010. Gray matter alterations in obsessive-compulsive disorder: an anatomic likelihood estimation meta-analysis. Neuropsychopharmacol. Off. Publ. Am. Coll. Neuropsychopharmacol. 35, 686-691. https://doi.org/10.1038/npp.2009.175

Roth, T.L., Lubin, F.D., Sodhi, M., Kleinman, J.E., 2009. Epigenetic mechanisms in schizophrenia. Biochim. Biophys. Acta 1790, 869-877. https://doi.org/10.1016/j.bbagen.2009.06.009

Rutten, B.P.F., Mill, J., 2009. Epigenetic mediation of environmental influences in major psychotic disorders. Schizophr. Bull. 35, 1045-1056. https://doi.org/10.1093/schbul/sbp104

Sagi, Y., Tavor, I., Hofstetter, S., Tzur-Moryosef, S., Blumenfeld-Katzir, T., Assaf, Y., 2012. Learning in the Fast Lane: New Insights into Neuroplasticity. Neuron 73, 1195-1203. https://doi.org/10.1016/j.neuron.2012.01.025

Sarpal, D.K., Robinson, D.G., Fales, C., Lencz, T., Argyelan, M., Karlsgodt, K.H., Gallego, J.A., John, M., Kane, J.M., Szeszko, P.R., Malhotra, A.K., 2017. Relationship between Duration of Untreated Psychosis and Intrinsic Corticostriatal Connectivity in Patients with Early Phase Schizophrenia. Neuropsychopharmacology. https://doi.org/10.1038/npp.2017.55

Scott, J., Leboyer, M., Hickie, I., Berk, M., Kapczinski, F., Frank, E., Kupfer, D., McGorry, P., 2013. Clinical staging in psychiatry: a cross-cutting model of diagnosis with heuristic and practical value. Br. J. Psychiatry 202, 243-245. https://doi.org/10.1192/bjp.bp.112.110858

Shang, J., Fu, Y., Ren, Z., Zhang, T., Du, M., Gong, Q., Lui, S., Zhang, W., 2014. The common traits of the ACC and PFC in anxiety disorders in the DSM-5: meta-analysis of voxel-based morphometry studies. PloS One 9, e93432. https://doi.org/10.1371/journal.pone.0093432

Shew, W.L., Yang, H., Yu, S., Roy, R., Plenz, D., 2011. Information capacity and transmission are maximized in balanced cortical networks with neuronal avalanches. J. Neurosci. Off. J. Soc. Neurosci. 31, 55-63. https://doi.org/10.1523/JNEUROSCI.4637-10.2011

Somel, M., Liu, X., Khaitovich, P., 2013. Human brain evolution: transcripts, metabolites and their regulators. Nat. Rev. Neurosci. 14, 112-127. https://doi.org/10.1038/nrn3372

Sprooten, E., Rasgon, A., Goodman, M., Carlin, A., Leibu, E., Lee, W.H., Frangou, S., 2016. Addressing reverse inference in psychiatric neuroimaging: Meta-analyses of task-related brain activation in common mental disorders. Hum. Brain Mapp. n/a-n/a. https://doi.org/10.1002/hbm.23486

Stephan, K.E., Baldeweg, T., Friston, K.J., 2006a. Synaptic plasticity and dysconnection in schizophrenia. Biol. Psychiatry 59, 929-939. https://doi.org/10.1016/j.biopsych.2005.10.005

Stephan, K.E., Baldeweg, T., Friston, K.J., 2006b. Synaptic Plasticity and Dysconnection in Schizophrenia. Biol. Psychiatry 59, 929-939. https://doi.org/10.1016/j.biopsych.2005.10.005

Stephan, K.E., Friston, K.J., Frith, C.D., 2009. Dysconnection in Schizophrenia: From Abnormal Synaptic Plasticity to Failures of Self-monitoring. Schizophr. Bull. 35, 509-527. https://doi.org/10.1093/schbul/sbn176

Sullivan, P.F., Kendler, K.S., Neale, M.C., 2003. Schizophrenia as a complex trait: evidence from a meta-analysis of twin studies. Arch. Gen. Psychiatry 60, 1187-1192. https://doi.org/10.1001/archpsyc.60.12.1187

Talati, A., Pantazatos, S.P., Schneier, F.R., Weissman, M.M., Hirsch, J., 2013. Gray matter abnormalities in social anxiety disorder: primary, replication, and specificity studies. Biol. Psychiatry 73, 75-84. https://doi.org/10.1016/j.biopsych.2012.05.022

Tang, W., Zhu, Q., Gong, X., Zhu, C., Wang, Y., Chen, S., 2016. Cortico-striato-thalamo-cortical circuit abnormalities in obsessive-compulsive disorder: A voxel-based morphometric and fMRI study of the whole brain. Behav. Brain Res. 313, 17-22. https://doi.org/10.1016/j.bbr.2016.07.004 
Tononi, G., Cirelli, C., 2014. Sleep and the price of plasticity: from synaptic and cellular homeostasis to memory consolidation and integration. Neuron 81, 12-34. https://doi.org/10.1016/j.neuron.2013.12.025

Turkheimer, F.E., Leech, R., Expert, P., Lord, L.-D., Vernon, A.C., 2015. The brain's code and its canonical computational motifs. From sensory cortex to the default mode network: A multiscale model of brain function in health and disease. Neurosci. Biobehav. Rev. 55, 211-222. https://doi.org/10.1016/j.neubiorev.2015.04.014

van Erp, T.G.M., Hibar, D.P., Rasmussen, J.M., Glahn, D.C., Pearlson, G.D., Andreassen, O.A., Agartz, I., Westlye, L.T., Haukvik, U.K., Dale, A.M., Melle, I., Hartberg, C.B., Gruber, O., Kraemer, B., Zilles, D., Donohoe, G., Kelly, S., McDonald, C., Morris, D.W., Cannon, D.M., Corvin, A., Machielsen, M.W.J., Koenders, L., de Haan, L., Veltman, D.J., Satterthwaite, T.D., Wolf, D.H., Gur, R.C., Gur, R.E., Potkin, S.G., Mathalon, D.H., Mueller, B.A., Preda, A., Macciardi, F., Ehrlich, S., Walton, E., Hass, J., Calhoun, V.D., Bockholt, H.J., Sponheim, S.R., Shoemaker, J.M., van Haren, N.E.M., Hulshoff Pol, H.E., Pol, H.E.H., Ophoff, R.A., Kahn, R.S., RoizSantiañez, R., Crespo-Facorro, B., Wang, L., Alpert, K.I., Jönsson, E.G., Dimitrova, R., Bois, C., Whalley, H.C., McIntosh, A.M., Lawrie, S.M., Hashimoto, R., Thompson, P.M., Turner, J.A., 2016. Subcortical brain volume abnormalities in 2028 individuals with schizophrenia and 2540 healthy controls via the ENIGMA consortium. Mol. Psychiatry 21, 547-553. https://doi.org/10.1038/mp.2015.63

Van Haren, N., Cahn, W., Hulshoff Pol, H., Kahn, R., 2012. The course of brain abnormalities in schizophrenia: can we slow the progression? J. Psychopharmacol. (Oxf.) 26, 8-14. https://doi.org/10.1177/0269881111408964

van Os, J., Reininghaus, U., 2016. Psychosis as a transdiagnostic and extended phenotype in the general population. World Psychiatry 15, 118-124. https://doi.org/10.1002/wps.20310

Videbech, P., Ravnkilde, B., 2004. Hippocampal volume and depression: a meta-analysis of MRI studies. Am. J. Psychiatry 161, 1957-1966. https://doi.org/10.1176/appi.ajp.161.11.1957

Vita, A., De Peri, L., Deste, G., Sacchetti, E., 2012. Progressive loss of cortical gray matter in schizophrenia: a meta-analysis and meta-regression of longitudinal MRI studies. Transl. Psychiatry 2, e190. https://doi.org/10.1038/tp.2012.116

Waiter, G.D., Williams, J.H.G., Murray, A.D., Gilchrist, A., Perrett, D.I., Whiten, A., 2004. A voxel-based investigation of brain structure in male adolescents with autistic spectrum disorder. Neurolmage 22, 619-625. https://doi.org/10.1016/j.neuroimage.2004.02.029

Whiteford, H.A., Degenhardt, L., Rehm, J., Baxter, A.J., Ferrari, A.J., Erskine, H.E., Charlson, F.J., Norman, R.E., Flaxman, A.D., Johns, N., Burstein, R., Murray, C.J., Vos, T., 2013. Global burden of disease attributable to mental and substance use disorders: findings from the Global Burden of Disease Study 2010. The Lancet 382, 1575-1586. https://doi.org/10.1016/S01406736(13)61611-6

Whitfield-Gabrieli, S., Thermenos, H.W., Milanovic, S., Tsuang, M.T., Faraone, S.V., McCarley, R.W., Shenton, M.E., Green, A.I., Nieto-Castanon, A., LaViolette, P., Wojcik, J., Gabrieli, J.D.E., Seidman, L.J., 2009. Hyperactivity and hyperconnectivity of the default network in schizophrenia and in first-degree relatives of persons with schizophrenia. Proc. Natl. Acad. Sci. U. S. A. 106, 1279-1284. https://doi.org/10.1073/pnas.0809141106

Yang, X., Si, T., Gong, Q., Qiu, L., Jia, Z., Zhou, M., Zhao, Y., Hu, X., Wu, M., Zhu, H., 2016. Brain gray matter alterations and associated demographic profiles in adults with autism spectrum disorder: A meta-analysis of voxel-based morphometry studies. Aust. N. Z. J. Psychiatry 50, 741-753. https://doi.org/10.1177/0004867415623858

Yang, Y., Nuechterlein, K.H., Phillips, O.R., Gutman, B., Kurth, F., Dinov, I., Thompson, P.M., Asarnow, R.F., Toga, A.W., Narr, K.L., 2012. Disease and genetic contributions toward local tissue volume disturbances in schizophrenia: a tensor-based morphometry study. Hum. Brain Mapp. 33, 2081-2091. https://doi.org/10.1002/hbm.21349

Yin, H.H., Knowlton, B.J., 2006. The role of the basal ganglia in habit formation. Nat. Rev. Neurosci. 7, 464-476. https://doi.org/10.1038/nrn1919 
Zarei, M., Mataix-Cols, D., Heyman, I., Hough, M., Doherty, J., Burge, L., Winmill, L., Nijhawan, S., Matthews, P.M., James, A., 2011. Changes in gray matter volume and white matter microstructure in adolescents with obsessive-compulsive disorder. Biol. Psychiatry 70, 10831090. https://doi.org/10.1016/j.biopsych.2011.06.032

Zhang, B., Lin, P., Shi, H., Öngür, D., Auerbach, R.P., Wang, Xiaosheng, Yao, S., Wang, Xiang, 2016. Mapping anhedonia-specific dysfunction in a transdiagnostic approach: an ALE meta-analysis. Brain Imaging Behav. 10, 920-939. https://doi.org/10.1007/s11682-015-9457-6

Abramowitz, J.S., Taylor, S., McKay, D., 2009. Obsessive-compulsive disorder. The Lancet 374, 491499. doi:10.1016/S0140-6736(09)60240-3

Andreasen, N.C., Carpenter, W.T., Kane, J.M., Lasser, R.A., Marder, S.R., Weinberger, D.R., 2005. Remission in schizophrenia: proposed criteria and rationale for consensus. Am. J. Psychiatry 162, 441-449. doi:10.1176/appi.ajp.162.3.441

Burcusa, S.L., lacono, W.G., 2007. Risk for Recurrence in Depression. Clin. Psychol. Rev. 27, $959-985$. doi:10.1016/j.cpr.2007.02.005

Eisen, J.L., Sibrava, N.J., Boisseau, C.L., Mancebo, M.C., Stout, R.L., Pinto, A., Rasmussen, S.A., 2013. Five-Year Course of Obsessive-Compulsive Disorder: Predictors of Remission and Relapse. J. Clin. Psychiatry 74, 233-239. doi:10.4088/JCP.12m07657

Emsley, R., Chiliza, B., Asmal, L., Harvey, B.H., 2013. The nature of relapse in schizophrenia. BMC Psychiatry 13, 50. doi:10.1186/1471-244X-13-50

Gitlin, M.J., Swendsen, J., Heller, T.L., Hammen, C., 1995. Relapse and impairment in bipolar disorder. Am. J. Psychiatry 152, 1635-1640.

Judd, L.L., Akiskal, H.S., Schettler, P.J., Endicott, J., Maser, J., Solomon, D.A., Leon, A.C., Rice, J.A., Keller, M.B., 2002. The long-term natural history of the weekly symptomatic status of bipolar I disorder. Arch. Gen. Psychiatry 59, 530-537.

Kendler, K.S., Thornton, L.M., Gardner, C.O., 2000. Stressful life events and previous episodes in the etiology of major depression in women: an evaluation of the "kindling" hypothesis. Am. J. Psychiatry 157, 1243-1251. doi:10.1176/appi.ajp.157.8.1243

Moylan, S., Maes, M., Wray, N.R., Berk, M., 2013. The neuroprogressive nature of major depressive disorder: pathways to disease evolution and resistance, and therapeutic implications. Mol. Psychiatry 18, 595-606. doi:10.1038/mp.2012.33

Perlis, R.H., Ostacher, M.J., Patel, J.K., Marangell, L.B., Zhang, H., Wisniewski, S.R., Ketter, T.A., Miklowitz, D.J., Otto, M.W., Gyulai, L., Reilly-Harrington, N.A., Nierenberg, A.A., Sachs, G.S., Thase, M.E., 2006. Predictors of recurrence in bipolar disorder: primary outcomes from the Systematic Treatment Enhancement Program for Bipolar Disorder (STEP-BD). Am. J. Psychiatry 163, 217-224. doi:10.1176/appi.ajp.163.2.217

Post, R.M., 1992. Transduction of psychosocial stress into the neurobiology of recurrent affective disorder. Am. J. Psychiatry 149, 999-1010. doi:10.1176/ajp.149.8.999

Roy-Byrne, P.P., Craske, M.G., Stein, M.B., 2006. Panic disorder. The Lancet 368, $1023-1032$. doi:10.1016/S0140-6736(06)69418-X

Scholten, W.D., Batelaan, N.M., Balkom, A.J. van, Penninx, B.W., Smit, J.H., Oppen, P. van, 2013. Recurrence of anxiety disorders and its predictors. J. Affect. Disord. 147, 180-185. doi:10.1016/j.jad.2012.10.031

Shergill, S.S., Murray, R.M., McGuire, P.K., 1998. Auditory hallucinations: a review of psychological treatments. Schizophr. Res. 32, 137-150. doi:10.1016/S0920-9964(98)00052-8 